Article

\title{
Autonomous Robotic Feature-Based Freeform Fabrication Approach
}

\author{
Xinyi Xiao ${ }^{1}$ and Hanbin Xiao ${ }^{2, *}$
}

check for

updates

Citation: Xiao, X.; Xiao, H.

Autonomous Robotic Feature-Based

Freeform Fabrication Approach.

Materials 2022, 15, 247. https://

doi.org/10.3390/ma15010247

Academic Editor: Seung Hwan Ko

Received: 3 November 2021

Accepted: 24 December 2021

Published: 29 December 2021

Publisher's Note: MDPI stays neutral with regard to jurisdictional claims in published maps and institutional affiliations.

Copyright: (c) 2021 by the authors Licensee MDPI, Basel, Switzerland. This article is an open access article distributed under the terms and conditions of the Creative Commons Attribution (CC BY) license (https:// creativecommons.org/licenses/by/ $4.0 /)$.
1 Mechanical and Manufacturing Engineering Department, Miami University, Oxford, OH 45069, USA; xiaox8@miamioh.edu

2 School of Transportation and Logistics Engineering, Wuhan University of Technology, Wuhan 430063, China

* Correspondence: xhbwhut@gmail.com

\begin{abstract}
Robotic additive manufacturing (AM) has gained much attention for its continuous material deposition capability with continuously changeable building orientations, reducing support structure volume and post-processing complexity. However, the current robotic additive process heavily relies on manual geometric reasoning that identifies additive features, related building orientations, tool approach direction, trajectory generation, and sequencing all features in a non-collision manner. In addition, multi-directional material accumulation cannot ensure the nozzle always stays above the building geometry. Thus, the collision between these two becomes a significant issue that needs to be solved. Hence, the common use of a robotic additive is hindered by the lack of fully autonomous tools based on the abovementioned issues. We present a systematic approach to the robotic AM process that can automate the abovementioned planning procedures in the aspect of collision-free. Typically, input models to robotic AM have diverse information contents and data formats, hindering the feature recognition, extraction, and relations to the robotic motion. Our proposed method integrates the collision-avoidance condition to the model decomposition step. Therefore, the decomposed volumes can be associated with additional constraints, such as accessibility, connectivity, and trajectory planning. This generates an entire workspace for the robotic additive building platform, rotatability, and additive features to determine the entire sequence and avoid potential collisions. This approach classifies the uniqueness of autonomous manufacturing on the robotic AM system to build large and complex metal components that are non-achievable through traditional one-directional AM in a computationally effective manner. This approach also paves the path in constructing an in situ monitoring and closed-loop control on robotic AM to control and enhance the build quality of the robotic metal AM process.
\end{abstract}

Keywords: robotic additive manufacturing; autonomous; collision-free

\section{Introduction}

Robotic AM's continuous rotatability of the building geometry enlarges the design space and complexity compared with traditional metal AM or subtractive processes. The conventional AM process is constrained in the single material accumulation direction that creates support structures underneath the overhang surfaces, specifically for the metal AM process. These supports must be removed using extra post-processing steps, and meanwhile, it could lead to a larger thermal distortion on the overhanging volumes [1]. In contrast, robotic AM achieves the continuous change of building orientation during the material deposition process, transforming overhang surfaces into a support-free manner under a different orientation. Therefore, utilizing such robotic AM can significantly reduce the heavy amount of support structures. Furthermore, changing deposition directions frequently can also avoid thermal stress concentration. Gaining the abovementioned advantages from robotic AM, a few issues come up with utilizing such a process are discussed below: 
1. Freeform fabrication on robotic AM is not constrained as a planar form. Since not all building features are below the deposition nozzle, the collision risk between the building volume and the machine increases while the complexity of the process increases.

2. The selection and determination of the additive features/volumes for the robotic AM heavily rely on human interpretation of the given 3D models.

Thus, the correctness of the volumetric decomposition into additive features and the determination of their orientations is urgently needed. Intuitively, enabling multiple orientations in a continuous deposition process mimics the Boolean operations of the 3D features in the computer aided design (CAD) feature-based modeling process. Therefore, such feature addition can change from the traditional one-directional build-up to multidirectional material deposition.

In the current robotic additive workflow, manual separation of the input geometry into a few AM features requires expert knowledge, and a feasible manufacturing plan cannot always be achieved. Figure 1 provides an entire workflow of the robotic multi-axis additive process. In this workflow, planning the manufacturing process requires identification, sequence without collision, and trajectory generation of all AM features. Two types of collisions may happen in the AM: local collision-among the AM features and the robot, and global collision-between the building substrate and the robot. Currently, the process planning remains manual or semi-manual activities driven by expertise.

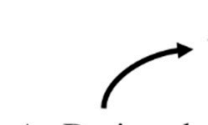

As-Designed 3D Model
Additively Manufactured

\section{Features}

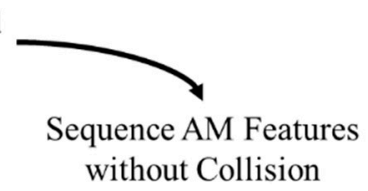

Assign Deposition Orientation for AM Features

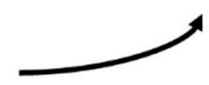

Export Sequenced Toolpath \{freeform layerwised toolpath, deposition orientation

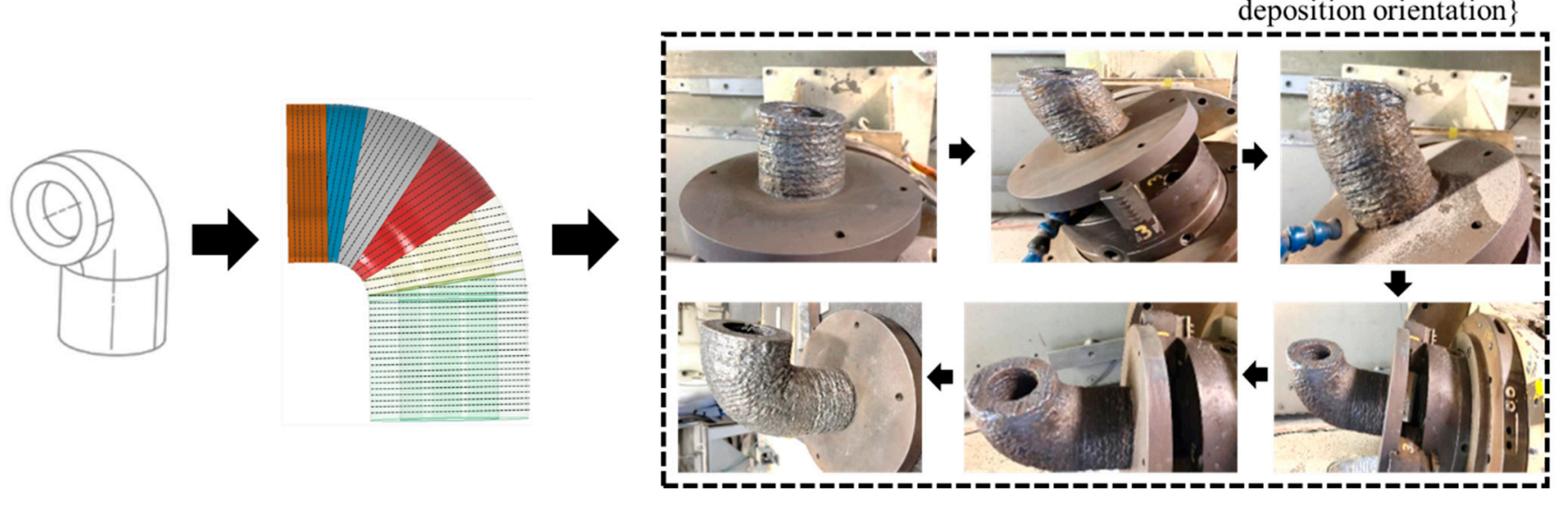

Figure 1. Overall workflow of robotic additive manufacturing.

As shown in Figure 1, manual decomposition of the given geometry is the prerequisite to automating such a multi-variability process. However, due to the design complexity for additive manufacturing, the input components cannot be simply decomposed through planar cuts [2]. Moreover, the planar decomposition creates a positional multi-axis material deposition, the utilization of the robotic freeform additive feature cannot be fully explored.

The major methods are concluded below for depositing materials through robotic additive manufacturing:

- Conformal freeform slicing;

- Adaptive slicing through the extracted medial axis.

These methods are capable of depositing material if a single feature is given to the system, such as an extrusion-based model, sweeping feature. However, a multi-feature complex model cannot be processed using the aforementioned two primary solutions. Therefore, the major task in designing a collision-free solution on a robotic AM system 
would require: (1) feature-based volumetric decomposition, (2) interaction among all decomposed AM features and the robot to ensure the collision-free processing condition.

Our approach to solving this problem involves the creation of valid convex-freeform surfaces from concave edges that can be applied to decompose the geometry. Nonetheless, not every concave edge loop on one geometry can be formed into a valid surface due to their shared surfaces with different curvatures. Our first proposed algorithm constructs a connectivity graph among all elements in a 3D model. Then, the attributes adjacency matrix is generated for grouping the concave edges within all elements. The convex-freeform shape surfaces can be generated from the grouped concave edges to ensure the zero possibility of local collision. The advantage of considering local collision into decomposing can be easily examined. After the decomposition, the only collision that needs to be considered in sequencing is the global collision. If the global collision is detected, it refers to the collide between the robotic deposition nozzle and the building substrate. Since constraining robot motion is a more complicated process and includes multiple decisions, the modification of the AM feature is a relatively straightforward adjustment. Our second algorithm will provide the modification method when a global collision exists.

The main contribution proposed in this field is to provide a computerized non-collision process planning method of any given CAD model on a robotic AM system without human interpretation. It has significant benefits in saving manual work time and providing a process solution on a robotic additive manufacturing system. The problems that will be solved in this paper are stated as follows:

(1) Decompose any given geometry into feature-based additive volumes.

(2) Sequence all AM features without a collision. The as-built CAD model will be modified if a global collision is detected. The new sequence will be updated on the modified as-built CAD model.

(3) Two-dimensional planar and three-dimensional freeform slicing methods will be applied to the sequenced AM features for generating the overall trajectory on the geometry.

\section{Literature Review}

Building up a geometry on a robotic AM system can be categorized into two methods:

1. Decompose the geometry into features that need to be built along with the associated building orientation.

2. Generate a non-planar adaptive slicing method for the overall geometry, instead of flat layer slicing with uniform layer thickness.

This section will discuss recent manufacturing strategies-decomposition and nonplanar adaptive slicing methods in the robotic additive system.

Decomposition in Robotic AM:

The significant problem among these methods lies in decomposing the geometry since sequencing and collision highly depend on the decomposition. Thus, providing an appropriate decomposition is the first and foremost step in autonomous robotic additive manufacturing.

The major solutions for delivering such an autonomous manufacturing system are shown in Table 1. A shared among these studies is that they only focused on automating partial steps in the process planning. The deficiencies of these approaches have been exposed in Table 1. 
Table 1. Capability of existing decomposition methodology and corresponding deficiencies.

\begin{tabular}{|c|c|}
\hline Varied Directional Deposition Strategy & Incapable \\
\hline $\begin{array}{l}\text { Projection-based Determination on the Manufacturable } \\
\text { Volume }[3,4]\end{array}$ & $\begin{array}{l}\text { - } \quad \text { Inefficient Decomposition; } \\
\text { - } \quad \text { All decomposed volume only uses planar deposition } \\
\text { - } \quad \text { Incapable of avoiding collision during manufacturing }\end{array}$ \\
\hline $\begin{array}{l}\text { Topological Feature Information [5-7] } \\
\text { Pairwise Distance Evaluation [8] } \\
\text { Shape Hierarchy Information [9] }\end{array}$ & $\begin{array}{l}\text { - Segmentation is not correlated with the manufacturing strategy } \\
\text { - Incapable of avoiding collision during manufacturing }\end{array}$ \\
\hline Guided Curve Assisted Multi-Axis Deposition [10-12] & $\begin{array}{l}\text { - Human interpretation is still required in specifying the deposition } \\
\text { orientation } \\
\text { - Decomposition the given geometry to a single feature still as a } \\
\text { manual step }\end{array}$ \\
\hline Chopper Partition $[13,14]$ & Only applicable for creating individual pieces using assembly \\
\hline $\begin{array}{c}\text { Beam-Guided Search for Overhanging Volumes [15] } \\
\text { Half-space Cutting Plane for Overhanging Volumes [16] } \\
\text { Buildable Volume Determination Based on } \\
\text { Manufacturability [17] }\end{array}$ & $\begin{array}{l}\text { - } \quad \text { All decomposed volume only uses planar deposition; } \\
\text { - } \quad \text { Cannot fully exploit the robotic multi-axis capability }\end{array}$ \\
\hline $\begin{array}{l}\text { Medial Axis Extraction and Volume Interpolation } \\
\qquad[18-20]\end{array}$ & $\begin{array}{l}\text { - Incapable of handling symmetrical geometries; } \\
\text { - } \quad \text { All decomposed volume only uses planar deposition; } \\
\text { - } \quad \text { Cannot fully exploit the robotic multi-axis capability }\end{array}$ \\
\hline $\begin{array}{l}\text { Voxelization Freeform layer-wise deposition [21] } \\
\text { Marching Cube decomposition [22] }\end{array}$ & $\begin{array}{l}\text { - Curved layers generation by counting shadowed voxels based on } \\
\text { building accessibility, thus skipping voxel-sized deposition } \\
\text { is normal } \\
\text { - Non-continuous path generation creating rough geometry finish }\end{array}$ \\
\hline $\begin{array}{l}\text { Adaptive Orientation using Offsetting Parallel } \\
\text { Contours [23] }\end{array}$ & $\begin{array}{l}\text { - Only Applicable to the geometries that have a consistent number } \\
\text { of parallel slicing contours }\end{array}$ \\
\hline
\end{tabular}

With the development of CAD, much attention has been paid to the 3D model decomposition and feature recognition from different aspects. Sundaram and Choi [3] started to segment the 3D model and the building orientation for multi-axis deposition in the early stage. The remaining volume that cannot be built through the building orientation will be perpendicular to the previous orientation. This method will create more than necessary segmented volumes, and the collision cannot be avoided if the input geometry is complicated. To describe the input 3D model, Lee and others [5-7] extracted topological information, such as vertices, edges, and faces, to create feature information. However, the segmented elements have no manufacturing meanings, thus preventing this strategy from being applied to robotic additive manufacturing. Similarly, Jain et al. [9] developed a hierarchy graph to describe the shape information, but this cannot prevent any collision among decomposed features. In addition, Liu et al. [8] evaluated the paired points distance on the 3D models and classify the points using such distance. Still, this strategy cannot provide meaningful decomposed volume for multi-axis additive manufacturing. Luo et al. [13] and Chen et al. [14] developed methods for assembling components to form a complete 3D model. These strategies do not apply to the condition in which all decomposed elements are manufactured through one process.

With the development of commercial multi-axis additive machines [24,25], Siemens NX [11] provides a semi-automated process planning for such operation, still requires lots of human interaction in decomposing the models to the suitable volumes of applying 2D planar or 3D conformal path trajectories. In addition to that, Rauch et al. [10] and Kapil et al. [12] used guided curves to specify the deposition orientation, but this process needs CAD expertise actions. Therefore, considering combining decomposition and 
multi-axis manufacturability, researchers developed a few automated process planning strategies [15-18] for depositing material along with multiple orientations in a support-less building manner. However, these approaches have the limitations that are concluded below:

(1) Xiao and Joshi [17], Wu et al. [15], and Murtezaoglu et al. [16] searched and created volumes that are allowable to be built support-less along with certain orientation. However, these process plans are primarily applied to positional multi-axis additiverotatability for positioning the geometry. Therefore, freeform deposition cannot be fully exploited.

(2) Foskey and other researchers [18-20] utilized medial axis information to specify the building orientations. However, it cannot be applied to the symmetrical structures and other deficiencies as described in 1)

(3) Kapil et al. [23] calculated the deposition orientation through the series of parallel layers offsetting information. However, this strategy can only be applied to the geometries with constant one contour in the layers.

(4) Dai et al. [21] counted the available voxel through layer-wised projection to form the freeform layer. However, this strategy is constrained by a low print quality caused by an easy-skipping voxel deposition and a noncontinuous deposition path.

Table 2 visualizes the decomposition difference between the existing and proposed methods.

Table 2. Decomposition results from existing methods and proposed one.

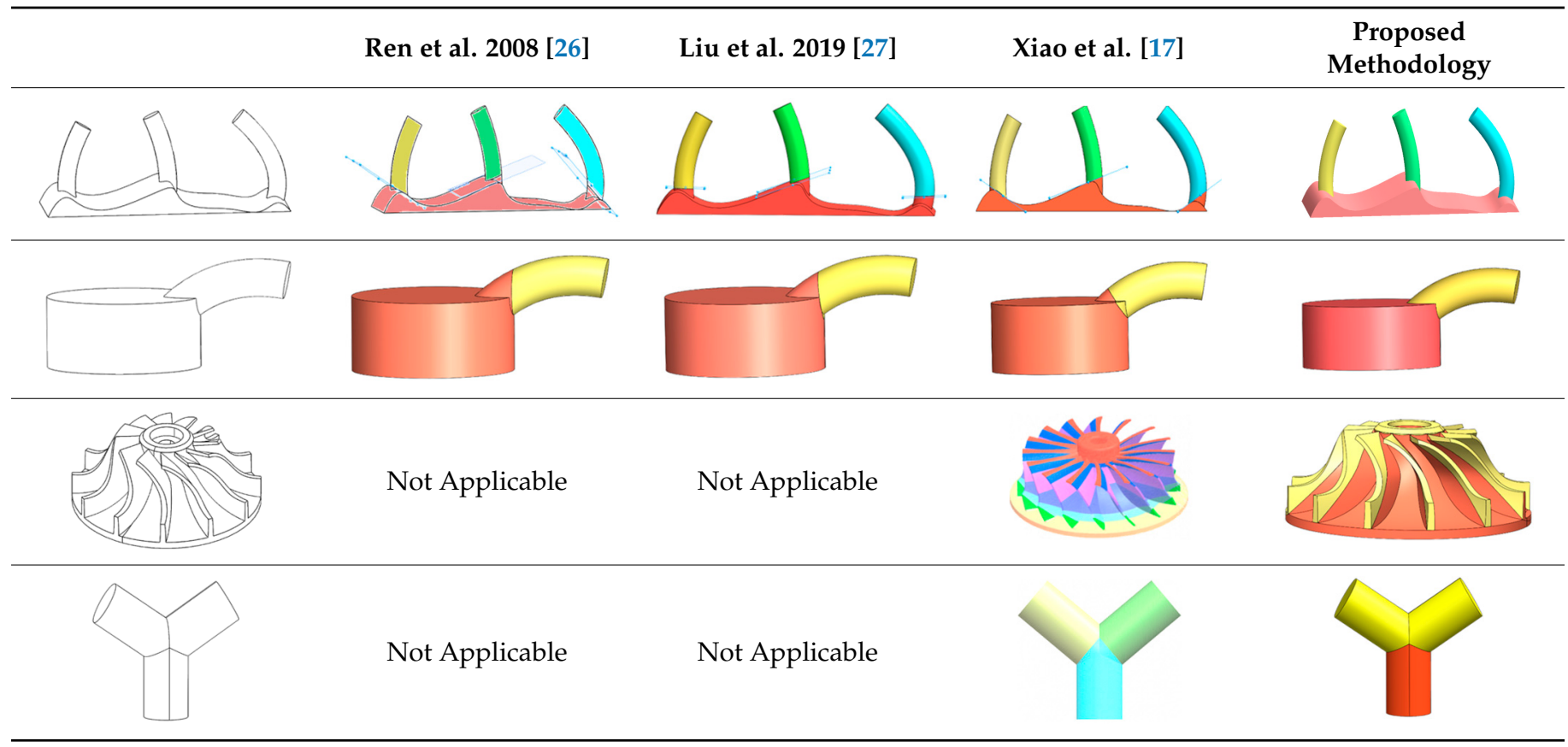

The major constraints of applying the abovementioned methods are listed:

(1) The potential failure of decomposition will happen on the geometry in which one concave edge loop locates on multiple faces.

(2) This constrains the input can only be tree-shaped structures.

(3) Only planar or revolving cuts are used in decomposing the volume. Therefore, the robotic capability is not fully utilized.

Slicing/Path Planning in Robotic AM:

Instead of allowing motion in a translation movement along with $\mathrm{x}, \mathrm{y}, \mathrm{z}$ axes, the robotic additive allows more degrees of freeform. Such a process can be visualized by stacking multiple planar/freeform layers to create 3D geometries. Table 3 presents the current technologies that use a robotic system to produce 3D models. 
Table 3. Robotic additive slicing and path planning strategies overview.

$\begin{array}{cc}\text { Slicing/Path Planning Method } & \text { Incapable } \\ \begin{array}{c}\text { Adaptive slicing algorithms based on the } \\ \text { cusp height and residual height [28] }\end{array} & \begin{array}{c}\text { Non-collision detection; } \\ \text { It cannot be applied to multi-feature } \\ \text { geometry }\end{array}\end{array}$

2.5D layerwise path planning $[29,30]$
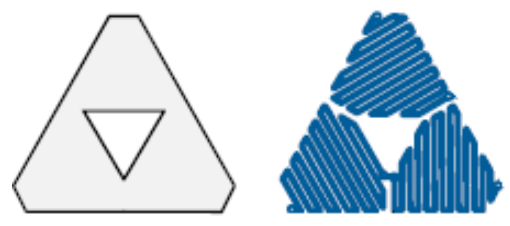

Planar-wised material accumulation

Planar surface additive strategy for productivity and geometric accuracy [31]

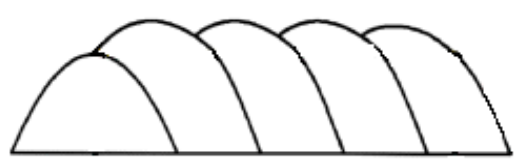

Planar-wised Solution
Freeform path planning on curvature surfaces [32-34]

Freeform weld path planning [35]

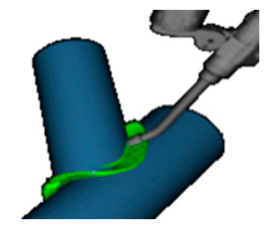

Not suitable for robotic additive 3D models
Only for the coating material, not for 3D model deposition
Spiral infill/climbing strategy [36]

Conformal layer AM [37-41]

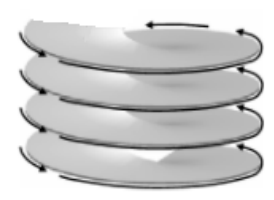

Only suitable for special geometric model 
limitations in building a 3D model that includes complex features. Thus, the feature-based deposition approach to overcome such limitations is urgently needed.

\section{Methodology}

\subsection{Problem Statement and Solution Overview}

The goal of decomposing the as-built 3D models is to reversely convert a multi-feature geometry to several single-body features. In Figure 2, we define the single-body feature as using one planar/freeform surface be the foundation and sweeping along one/multiple guide curves. By sweeping the foundation surface through the guide curves, the 3D feature can be modeled.
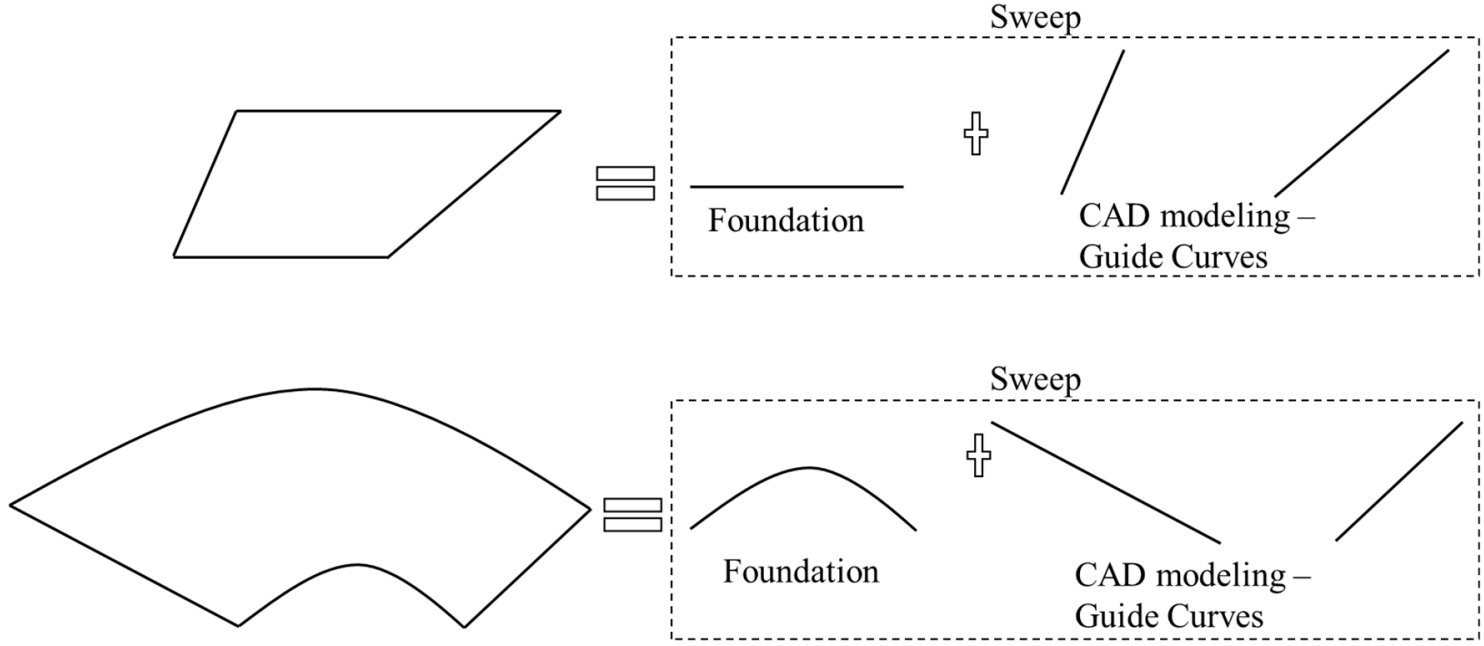

Figure 2. AM volume satisfying requirements in CAD modeling system.

However, only considering decomposing the model to several single-body features cannot ensure the non-local collision condition. Thus, an approach is proposed to ensure the decomposed feature can meet such requirements. Essentially, the local collision can happen between the AM feature and the robotic deposition nozzle because of the freeform layering. The creation of the freeform geometry would allow: (1) portion of the geometry higher than the robotic deposition nozzle along with the building orientation; (2) the oriented robotic nozzle interfere with the freeform layer concave region on the freeform geometry. Figure 3 presents the two types of local collisions discussed in this paper.
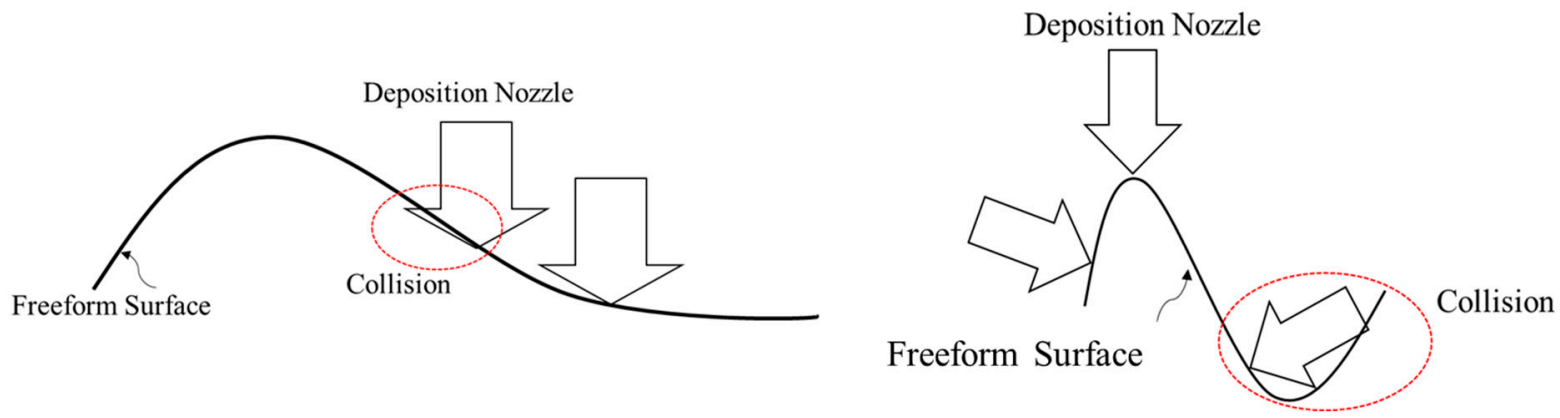

Figure 3. Local collision conditions.

The first type of collision can be avoided by modifying the orientation of the nozzle to be perpendicular to the freeform surface. However, the second type of collision may happen due to the varied machine tool size and the freeform surface topology. The local collision may occur at the concave zone on the surface. 
In order to prevent such local collision problems and satisfy the decomposed volume modeling condition, the problem can be defined:

- $\mathrm{M}=\sum$ Sweep Volume ;

- Sweep Volume $_{i}=\operatorname{sweep}\left(\right.$ foundation surface $_{\mathrm{i}}$, guide curves $\left._{\mathrm{i}}\right)$;

- $\quad$ foundation surface i $=$ convex;

- Sweep Volume $_{i} \cap$ Sweep Volume $_{j}=$ foundation surface $_{j}$;

- Sweep Volume $_{\mathrm{i}}=\operatorname{conformal} \sum\left(\right.$ foundation surface $\left._{\mathrm{i}}\right)$.

The concave edges exist in any model containing two or more CAD modeling features, and they can be considered the intersecting edges of the joining features. The formation of the decomposing surfaces (Figure 4) is unique and straightforward for fulfilling the following conditions:

- concave $_{\mathrm{i}} \in$ face $_{\mathrm{m}, \mathrm{n}}$, when face $\mathrm{m}_{\mathrm{m}}$, face $_{\mathrm{n}}$ are adjacent $\mid$ curvature $\left(\right.$ face $\left._{\mathrm{m}}\right)=$ curvature $\left(\right.$ face $\left._{\mathrm{n}}\right)$;

- $\quad$ surface $_{i}=$ concvex fill $\left(\right.$ concave $\left._{i}\right)$;

- $\mathrm{D}_{\mathrm{i}}=\operatorname{convex}\left(\sum\right.$ surface $\left._{\mathrm{i}}\right)$, if surface $_{\mathrm{i}}$ are adjacent.

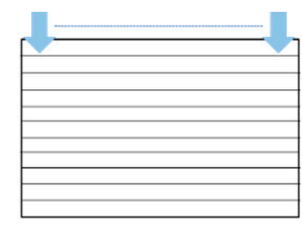

a) $2 \mathrm{D}$ conformal slicing method

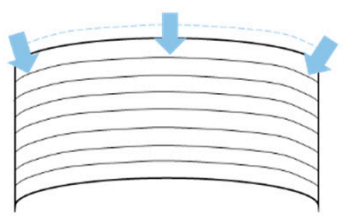

b) 3D conformal slicing method

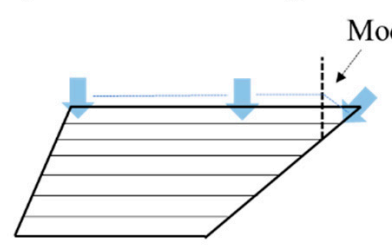

c) $2 \mathrm{D}$ conformal slicing method (with modified zone)

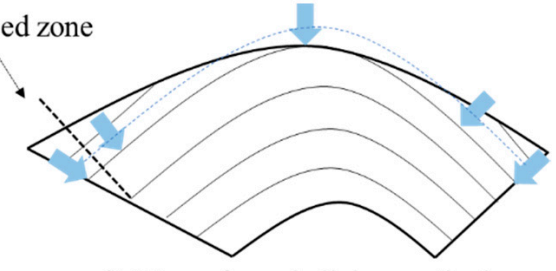

d) 3D conformal slicing method (with modified zone)

Figure 4. AM volume slicing strategies on a robotic system using adaptive conformal trajectory.

Through the decomposition, the individual AM volumes need to be built through 2D planar or 3D freeform conformal trajectory (shown in Figure 4). These conformal trajectories require adaptive modifications on the "overhanging" volumes by re-orienting the robotic deposition nozzle. This adaptive modification allows the overhanging regions to be built supportless.

From Figure 4, we can see that the overhang volume exists in both conditions. The traditional conformal trajectory uses parallelly slicing technique to build up the geometry and nearly does not allow any overhang volume. Instead, the overhang zone per layer utilizes the modified process parameters and the nozzle orientation to adjust the deposition volume. The modified orientation and the related process parameters will be discussed in the later section.

\subsection{Proposed Approach}

The prerequisites of processing decomposition for avoiding local collision are proposed in the previous section. This section comprises three algorithms used for decomposing, sequencing, and generating trajectories for a robot and segmenting the geometry into singlebody features as the additive features. All the single-body features are local collision-free, satisfying the abovementioned conditions. The overview of Algorithm 1 from the input as-built CAD model to the decomposed single-body feature is presented in Figure 5. 


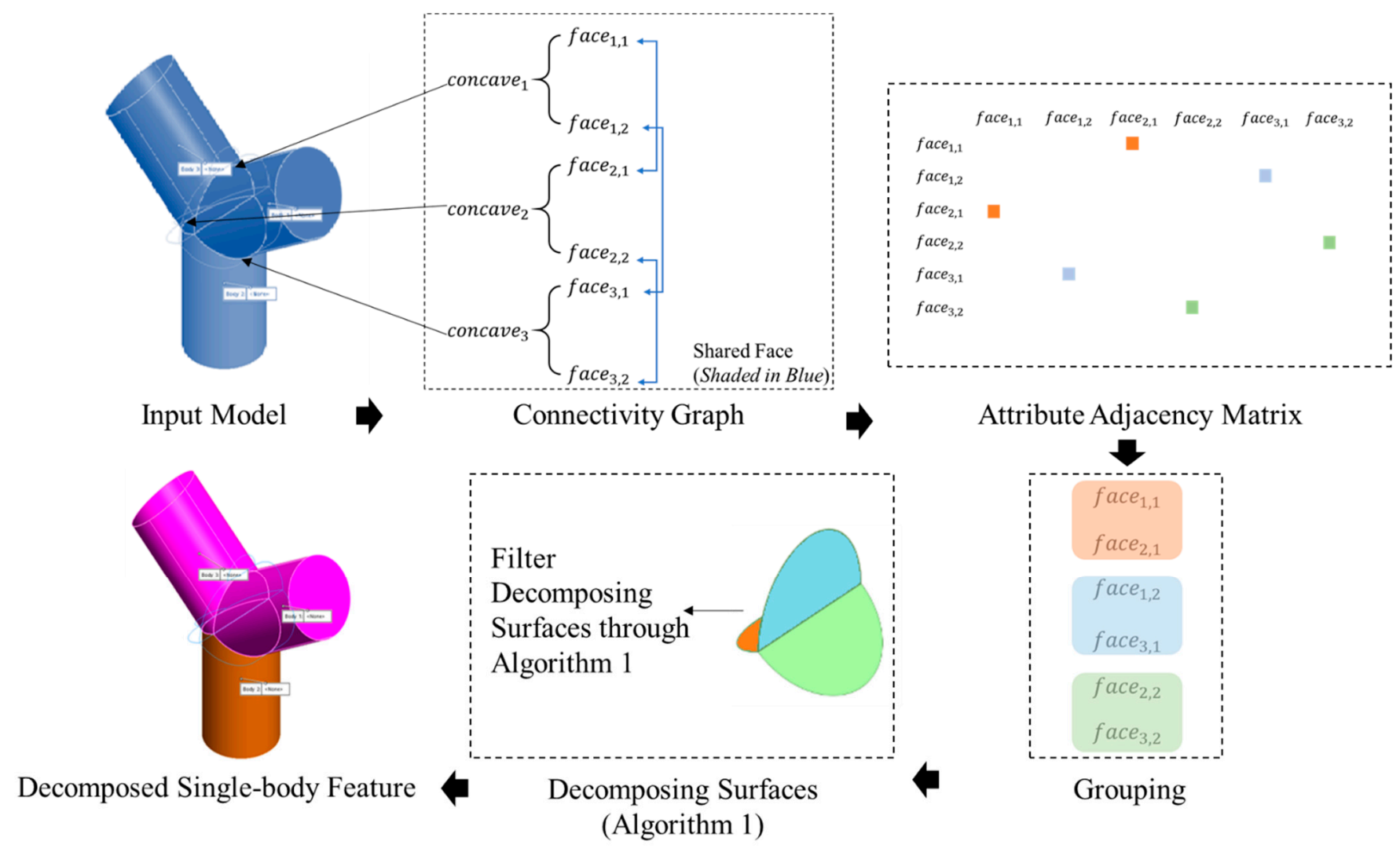

Figure 5. Overall workflow of a robotic AM single-body feature decomposition.

After obtaining single-body features from Algorithm 1, Algorithm 2 can process all decomposed single-body features into a non-global collision sequence and provide conformal slicing orientation for all the decomposed features. If the global collision can be detected, the as-built CAD model will be modified to compensate for the collision risk. Later, algorithm 3 creates trajectory on AM features, including the robotic deposition nozzle approaching direction. All these volumes will be applied with adaptive conformal trajectories. If necessary, modifying the process parameters and the approaching orientation is needed.

\subsubsection{Algorithm 1: Decomposing into $\mathrm{V}_{\mathrm{i}}$}

This section presents the autonomous decomposition algorithm for assigning the given as-built CAD model into single-body features built through the above-mentioned adaptive conformal trajectories.

An example has been processed through Algorithm 1 (Figures 6 and 7) for illustrating the decomposition process. All colored edges shown in Figure 7a are the concave edges, and their corresponding color represents the group based on the connectivity graph and attributes adjacency matrix. From Algorithm 1, a connectivity graph can be computed for grouping the concave edges. In Figure 6, concave edges are first extracted, and their adjacent faces on the input model can be obtained as well. If a shared adjacent face of two or more concave edges, these concave edges will be grouped and form the attribute adjacency matrix. 
Algorithm 1: Decomposition of as-built into single-body features. Autonomous creation of decomposed single-body features.

Input: As-built 3D model M, initial building orientation vector $(\vec{N})$

Output: Decomposed volumes

1. Extract all edge $\mathrm{k}_{\mathrm{k}}$, face $\mathrm{f}_{1}$ on $\mathrm{M}$

2. Extract concave $\mathrm{i}_{\mathrm{i}}$, if $\measuredangle\left(\right.$ face $_{\mathrm{q}}$, face $\left._{\mathrm{q}+1}\right)\left\langle\pi \|\right.$ face $_{\mathrm{q}} \cap$ face $_{\mathrm{q}+1}=$ edge $_{\mathrm{k}}$

3. If face f1 $_{11} \cap$ face $_{12}=$ concave $_{i}$

4. Connect $_{\mathrm{i}}=\left\{\right.$ face $_{11}$, face $\left._{12}\right\}$, Compute Connectivity Graph of concave_edge $\mathrm{i}$

5. End

6. If $\forall$ Curvature $\left(\right.$ Connect $\left._{\mathrm{i}}\right)=\forall$ Curvature Connect $\left._{\mathrm{j}}\right)|| \forall$ Connect $_{\mathrm{i}} \cap \forall$ Connect $_{\mathrm{j}} \neq \varnothing$

7. group $_{\mathrm{m}}=\left\{\right.$ concave $_{\mathrm{i}}$, concave $\left._{\mathrm{j}}\right\}$

8. Attribute adjacency matrix $=\left[\right.$ group $\left._{\mathrm{m}}\right]$

9. End

10. $\mathrm{S}_{\mathrm{m}}=$ convex_hull(Attribute adjacency matrix $\left.\mathrm{m}\right), \mathrm{m} \in[1,2, \ldots$,\#group $]$

11. If $S_{\mathbf{x}} \cap S_{\mathrm{x}+1} \neq \varnothing$

12. Space $_{x, x+1}=\left\{\mathrm{S}_{\mathrm{x}}, \mathrm{S}_{\mathrm{x}+1}\right\} \ni \vec{N}$

13. $\theta_{x, x+1} \in$ Space $_{x, x+1} \| \theta_{x, x+1}=\measuredangle\left\{\mathrm{S}_{\mathrm{x}}, \mathrm{S}_{\mathrm{x}+1}\right\}$

14. If $\theta_{x, x+1}<\pi$

15. $\mathrm{D}_{\mathrm{x}}=\mathrm{S}_{\mathrm{x}}$

16. $\quad$ Elseif $\theta_{x, x+1}>\pi$

17. $\mathrm{D}_{\mathrm{x}}=$ convex_hull $\left(\cup\left\{\mathrm{S}_{\mathrm{x}}, \mathrm{S}_{\mathrm{x}+1}\right\} \vec{N}\right)$

18. End

19. End

20. Decompose $\mathrm{M}$ by $\cup \mathrm{D}_{\mathrm{x}}$ into single - body Features $\left(\mathrm{V}_{\mathrm{y}}\right)$

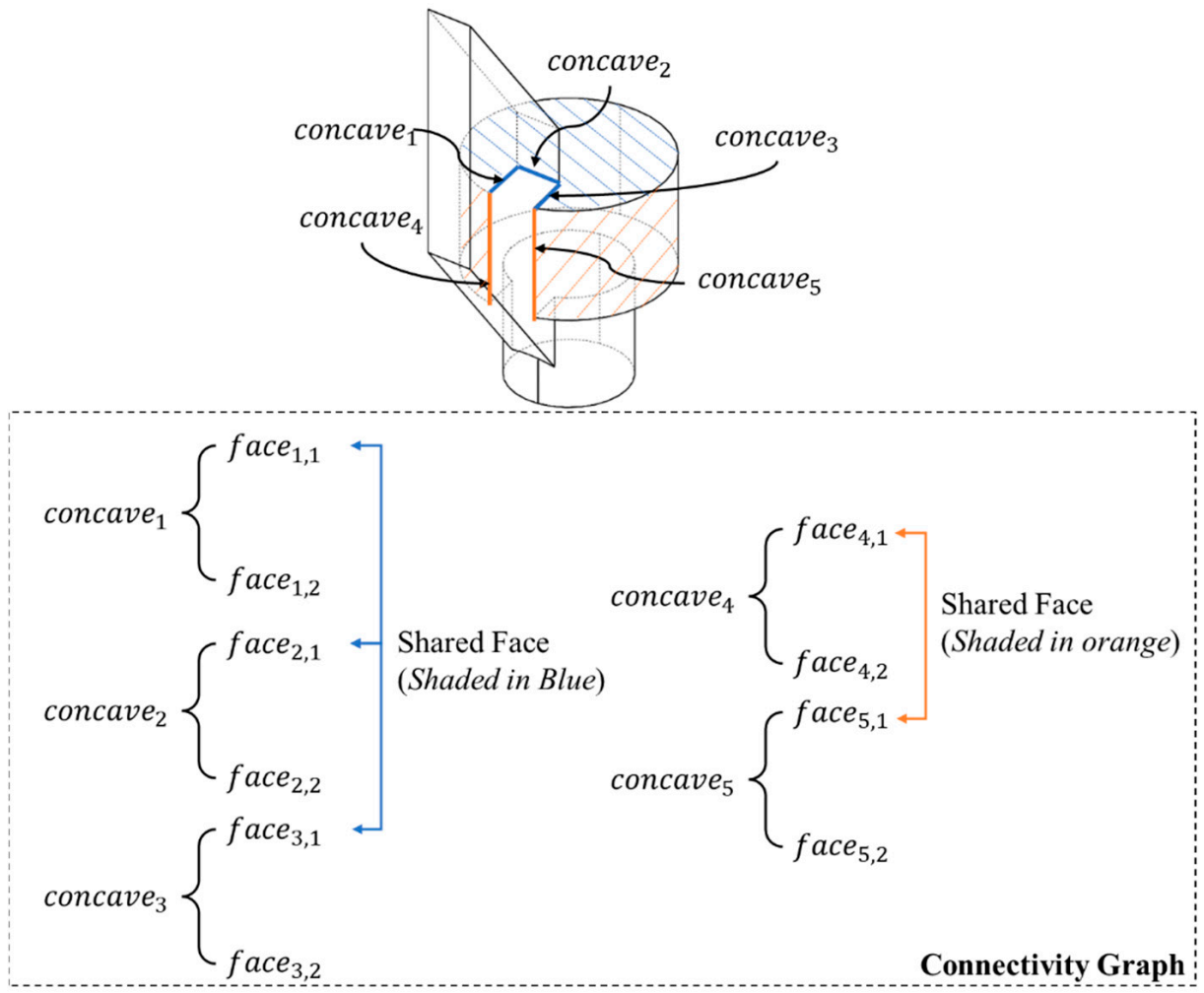

Figure 6. Connectivity graph generation by Algorithm 1 . 


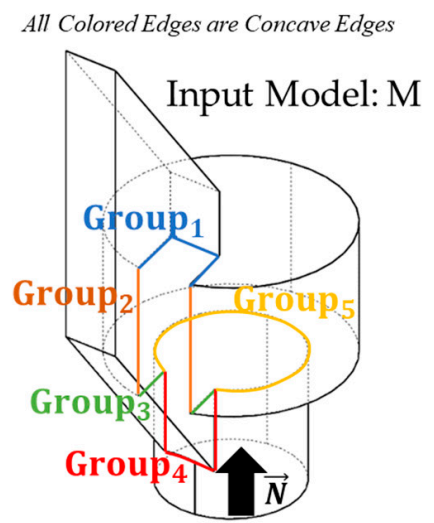

(a) Input Model and Grouped Concave Edges

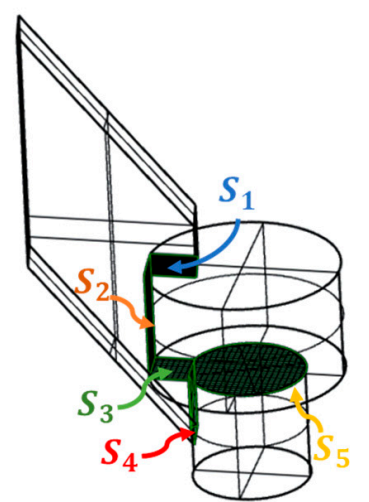

(b) Surfaces Created by Grouped Concave Edges

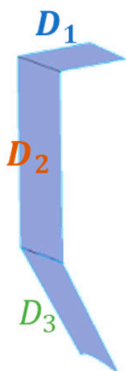

(c) Decomposing Surfaces

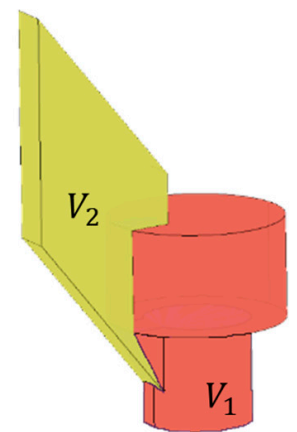

(d) Decomposition Result

Figure 7. Visualized workflow of Algorithm 1.

In Figure 6, concave edges (1-3) share a face (shaded in blue) based on the connectivity graph. Therefore, these three concave edges are grouped. The same theory can be applied to concave edges (4-5). These two edges can then be grouped to be the same attribute.

In Figure 7, the concave edges and the adjacent face curvature and connectivity group these edges are computed. Each grouped concave edge can then create the surfaces in $b$. If the subspace created by the adjacent surfaces (Figure $7 \mathrm{~b} \mathrm{~S}_{3}, \mathrm{~S}_{4}$ ) includes the initial building orientation is convex, the new decomposing surface in Figure $7 c \mathrm{D}_{3}$ will be created. The new decomposing surface is created by applying convex hull to the subspace that does not include the initial building orientation vector. The final decomposition result using these decomposing surfaces is shown in Figure $7 \mathrm{~d}$.

Since this decomposition algorithm is dependent on the initial building orientation, we present the different decomposition results by applying different initial orientations. All decomposed volumes $\left(\mathrm{V}_{\mathrm{y}}\right)$ have a decomposing surface $\left(\mathrm{D}_{\mathrm{x}}\right)$ that is convex-freeform that ensures the foundation surface on the decomposed feature is convex for avoiding local collision. The difference by applying different initial orientations to the identical model is shown in Figure 8.
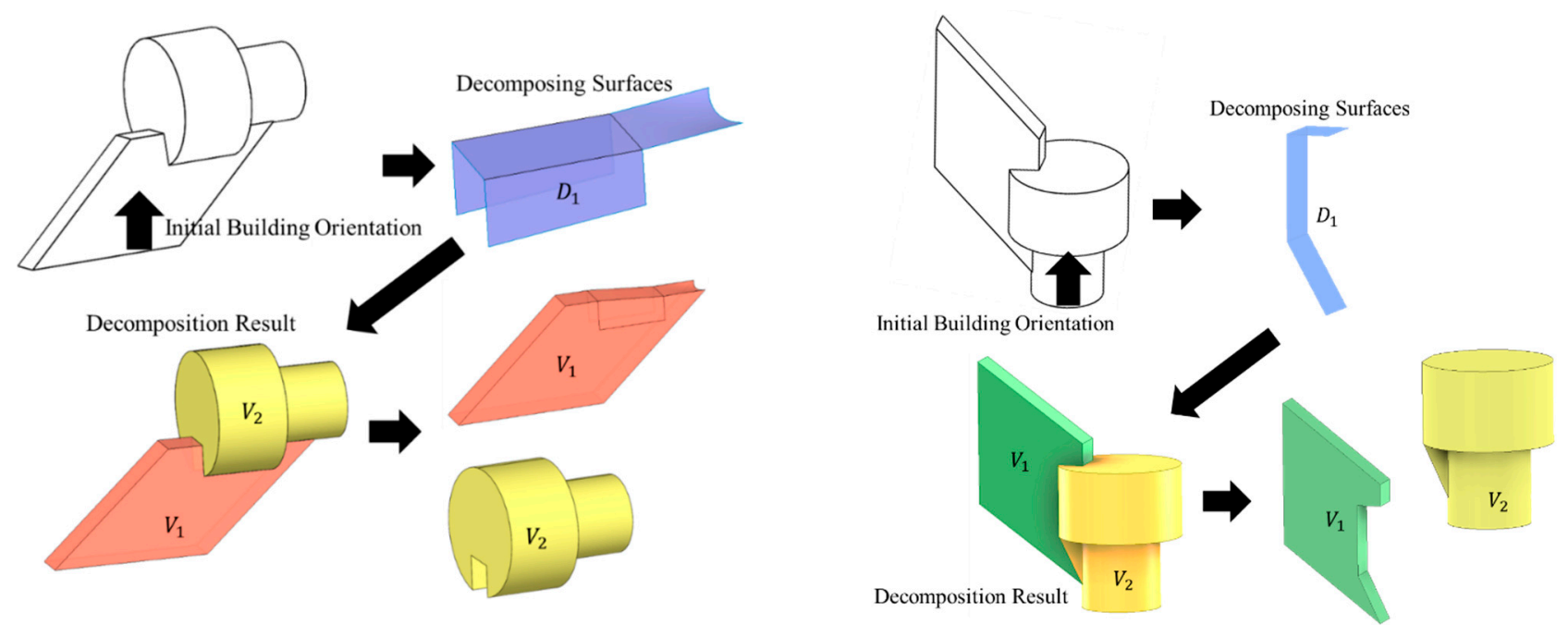

Figure 8. Decomposed single-body features of identical part by applying different initial orientation.

\subsubsection{Algorithm 2: Sequencing and Modifying As-Built Model If Necessary}

The local and global collision needs to be avoided in developing the autonomous robotic AM process. The local collision avoidance can be achieved through convex-freeform 
decomposition by Algorithm 1. The global collision will be detected through sequencing all single-body features with robotic motion into consideration. The detail of the algorithm is shown below. The as-built CAD model will be modified using the proposed algorithm if a global collision exists.

\footnotetext{
Algorithm 2: Sequencing Single-Body Features $\left(\mathrm{V}_{\mathrm{y}}\right)$ and Modify As-built Model $(\mathrm{M})$. Sequencing and modification of as-built model.
}

Input: $\mathrm{V}_{\mathrm{y}}$ from Algorithm 1, initial building orientation $\{\mathrm{N}\}$, initial building surface $\{S\}$,

Substrate \& Building Table Geometry $\{B\}$

Output: Sequence $\left\{\mathrm{V}_{\mathrm{y}}\right\}=\left\{\mathrm{R}_{\mathrm{i}}\right\}$, Conformal Slicing Orientation $\mathrm{N}\left(\mathrm{R}_{\mathrm{i}} \mid \mathrm{V}_{\mathrm{yi}}\right)$, Modified as-built

1. $\mathrm{R}_{0}=\mathrm{S}, \mathrm{R}_{1}\left(\mathrm{~V}_{\mathrm{y}}\right) \mid \exists \mathrm{V}_{\mathrm{y}} \cap \mathrm{S} \neq \emptyset$, Normal $\left(\mathrm{V}_{\mathrm{y}} \cap \mathrm{S}\right)=\mathrm{N}$

2. ITERATE for $R_{i}=V_{y i}, i=i+1$

3. If $\mathrm{V}_{\mathrm{yi}} \cap \mathrm{V}_{\mathrm{yj}} \neq \varnothing \& \& \mathrm{~V}_{\mathrm{yi}} \cap \mathrm{V}_{\mathrm{yk}} \neq \varnothing$

4. $\quad \mathrm{R}_{\mathrm{i}+1}=\mathrm{U}\left\{\mathrm{V}_{\mathrm{yj}}, \mathrm{V}_{\mathrm{yk}}\right\}$

5. End

6. UNTIL Last in $\mathrm{V}_{\mathrm{y}}$

7. Connectivity Sequence: $R_{1}\left(U V_{y}\right) \rightarrow R_{2}\left(U V_{y}\right) \rightarrow \ldots \rightarrow R_{n}\left(U V_{y}\right)$

8. Adjacency Surface $\left\{f_{\mathrm{y}, \mathrm{i}}\right\}=\left[\mathrm{R}_{\mathrm{i}}\left|\mathrm{V}_{\mathrm{yi}} \cap \mathrm{R}_{\mathrm{i}-1}\right| \mathrm{V}_{\mathrm{yi}-1}\right]$

9. $\quad \mathrm{V}_{\mathrm{y}}$ Conformal Slicing Orientation: $\mathrm{N}\left(\mathrm{R}_{\mathrm{i}} \mid \mathrm{V}_{\mathrm{yi}}\right)=\operatorname{Normal}\left(\mathrm{f}_{\mathrm{y}, \mathrm{i}}\right)$

10. If $\exists \operatorname{convex}\left\{\sum \operatorname{slice}_{\mathrm{k}}, \mathrm{B}\right\}-\operatorname{convex}\left\{\sum \operatorname{slice}_{\mathrm{k}}\right\} \in \operatorname{proj}_{\mathrm{s}}\left\{\sum \operatorname{slice}_{\mathrm{k}}\right\}$

11. Print: Global Collision

12. overhang $_{\mathrm{V}_{\mathrm{y}}}=\mathrm{V}_{\mathrm{y}}-\sum$ slice $_{\mathrm{k}-1}$

13. ELSE If $\exists$ Face $_{\mathrm{i}} \cap$ Face $_{\mathrm{k}} \neq \varnothing|| \operatorname{Normal}\left(\right.$ Face $\left._{\mathrm{i}}\right) \perp \mathrm{N} \| \operatorname{Normal}\left(\right.$ Face $\left._{\mathrm{k}}\right) \#-\mathrm{N}$

14. Print: Global Collision

15. overhang $\mathrm{v}_{\mathrm{y}}=$ Face $_{\mathrm{k}}$

16. End

17. Add $=$ convex_hull(overhang $\mathrm{V}_{\mathrm{y}^{\prime}}$ slice $\left._{1}\left\{\mathrm{~V}_{\mathrm{y}}\right\}\right)$

Modification of

As-Built

Two examples of applying Algorithm 2 for detecting global collision are shown in Figure 9. In Figure 9a, due to the substrate and the robotic motion constraints, the nozzle (shown in grey) has no feasibility to achieve such overhanging surface area. Therefore, the global collision will happen here. Thus, the "Add" volume will be defined and applied to the as-built model. In Figure 9b, the nozzle has no access to the bridging geometry in the structure (we assume metal additive allows no bridging capabilities). This situation cannot be avoided due to the as-built model bridging structure. Thus, this situation is categorized into the global collision, which requires modification on the as-built model. The "Add" volume is calculated from Algorithm 2 and will be used to modify the as-built geometry for considering the building's feasibility. 


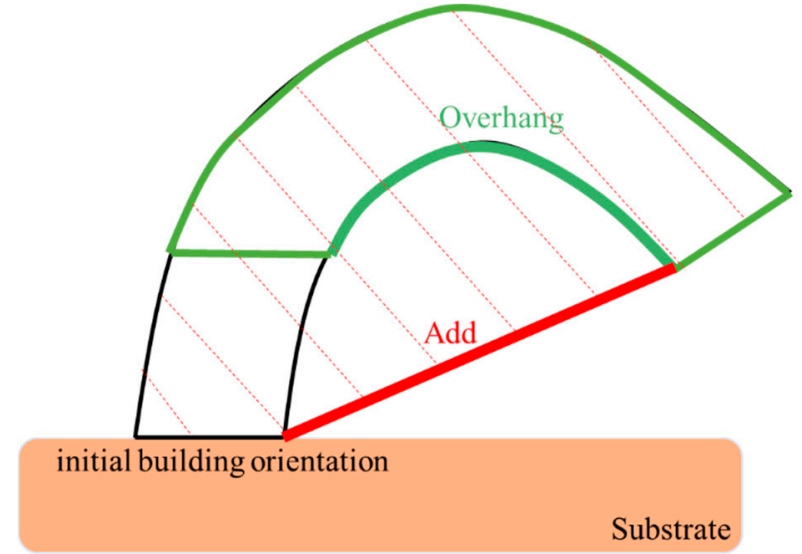

a) Global Collision Condition 1

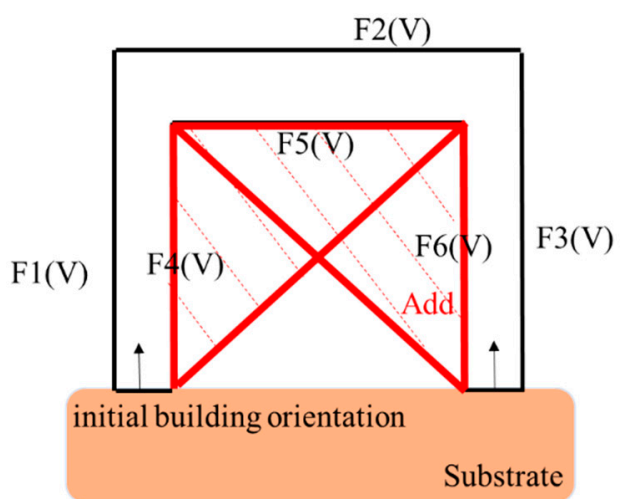

b) Global Collision Condition 2

Figure 9. Two global collision conditions that can be detected and avoided by Algorithm 2.

3.2.3. Algorithm 3: Trajectory Generation and Robotic Deposition Nozzle Approaches

In this section, Algorithm 3 will generate material deposition trajectories on the planar/freeform layers on the single-body features with adaptive modifications on the robotic deposition nozzle approaching orientations.

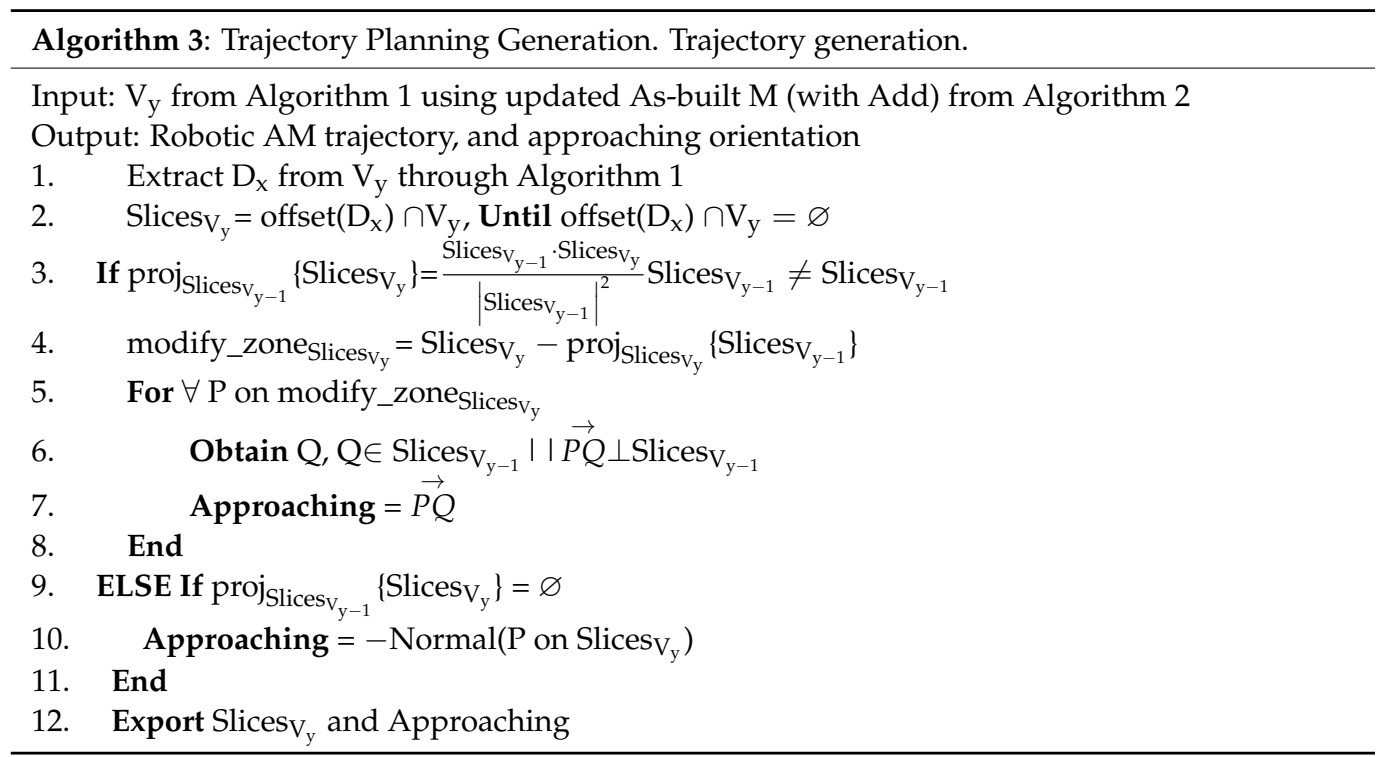

Algorithm 3 provides a strategy by orienting the nozzle direction from a perpendicular position to a tilted angle to fill the overhang volume.

\section{Implementation and Result}

Few examples are selected to demonstrate the effectiveness and efficiency of the proposed algorithms. One model would consume an experienced worker around $100 \mathrm{~h}$ without providing a feasible process planning to avoid collisions. The algorithms are coded into software by Rhino Grasshopper, C\#, and Python running on an Intel i7-9750H CPU 2.60 GHz computer. All models cannot be autonomously manufactured without decomposing into buildable AM volumes or requiring extra attention in avoiding a collision.

Figures 10-13 represent the processing results by providing the same as-built model (model (a)) with different initial building orientation and substrate size conditions. The decomposed single-body features with the manufacturing orientations and sequence are shown as well. 


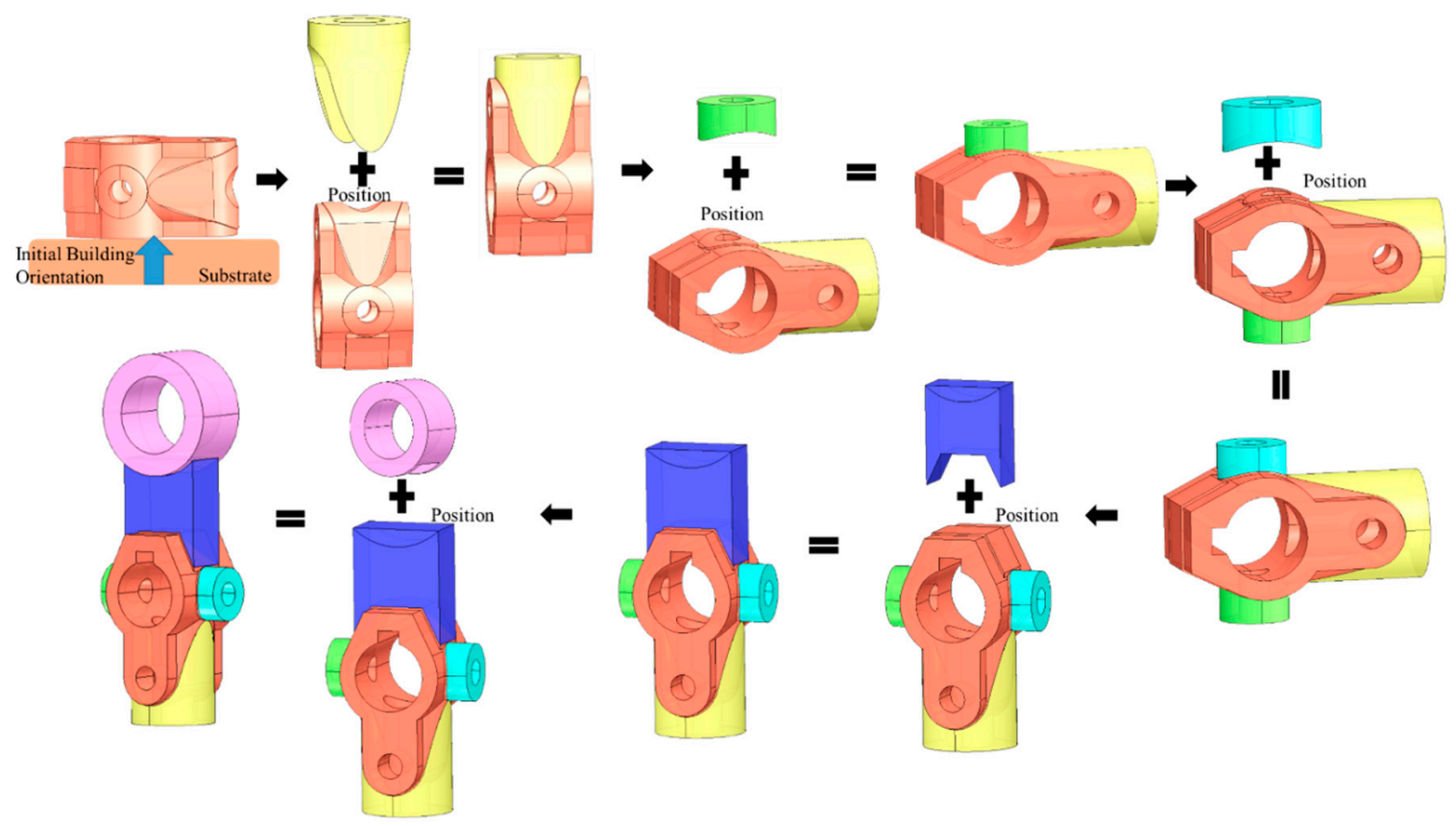

Figure 10. Process planning with first defined initial building orientation for model (a).

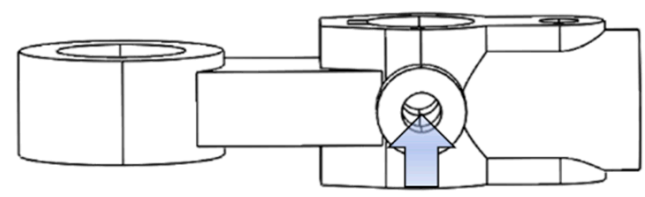

(a) Input Model with Initial Building Orientation

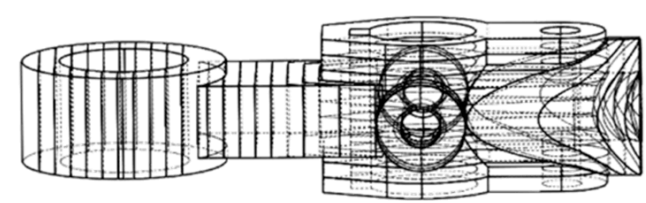

(b) Model Overall Toolpath Visualization

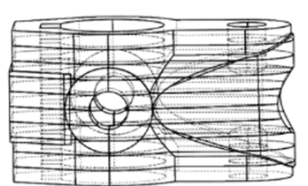

7
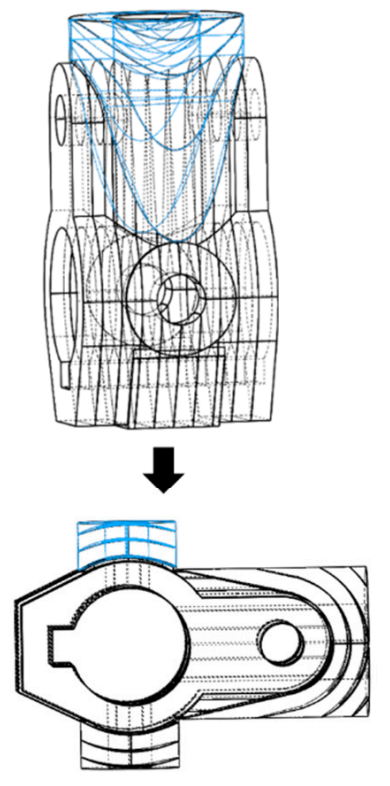

(c) Toolpath on Each processing volumes

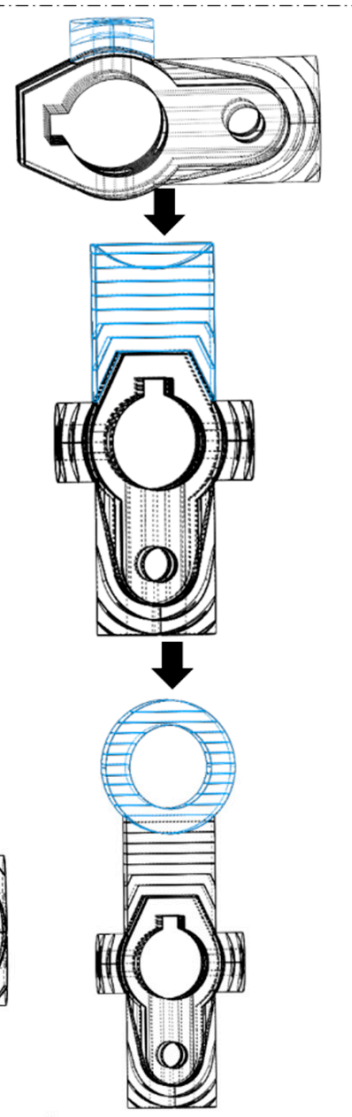

s

Figure 11. Trajectory accumulation on model with first defined initial building orientation for model (a). 


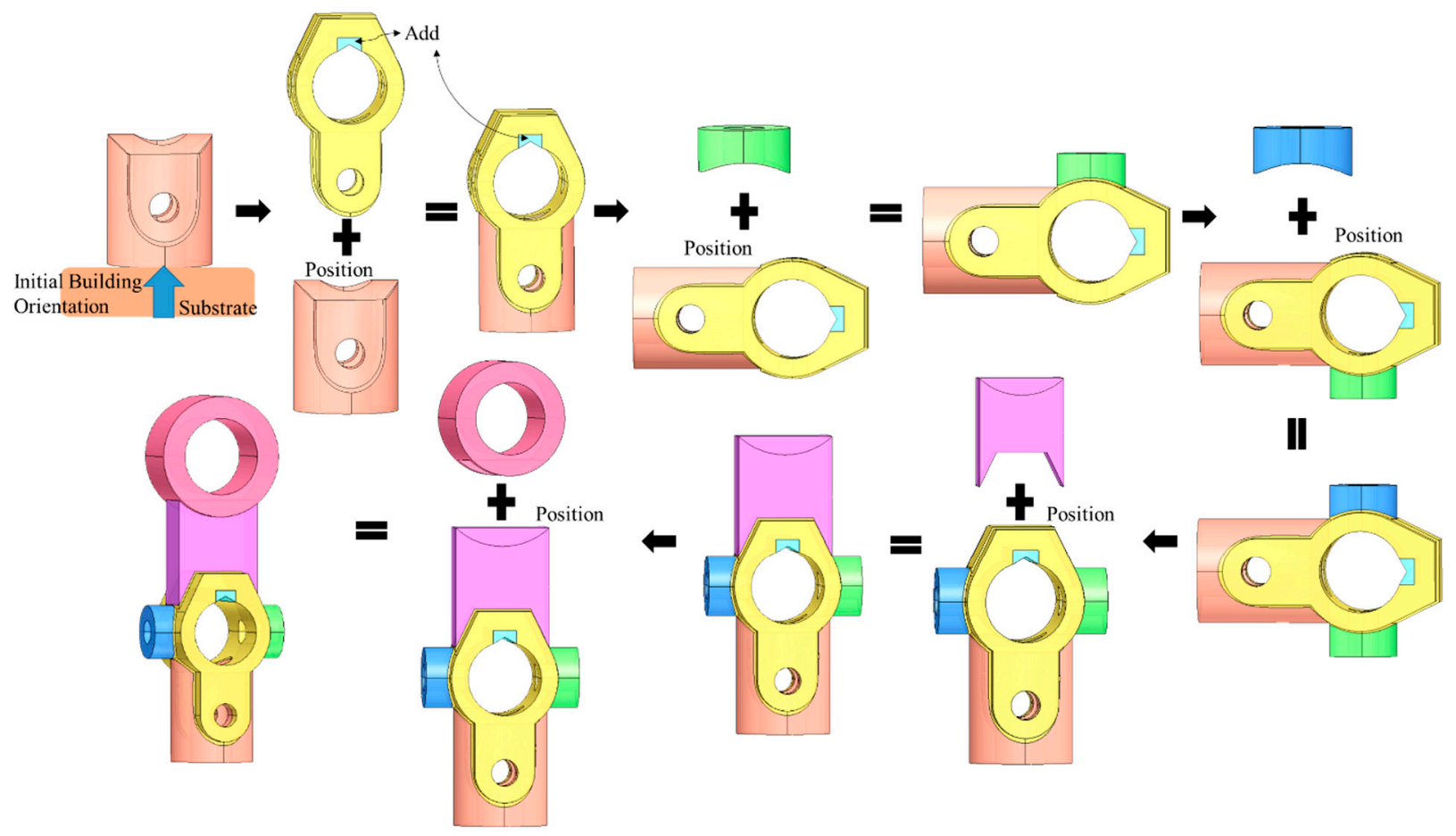

Figure 12. Process Planning with second defined initial building orientation for model (a).

(a) Input Model with Initial Building Orientation

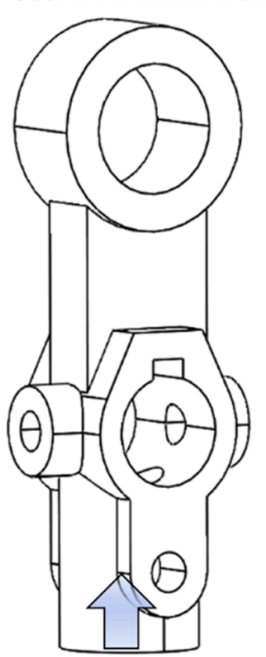

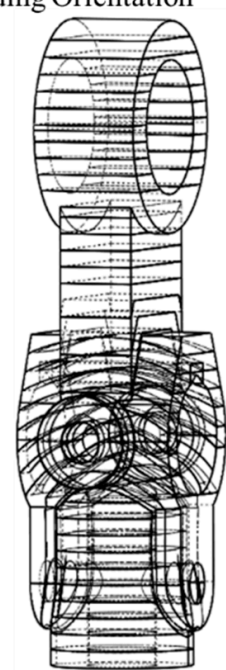

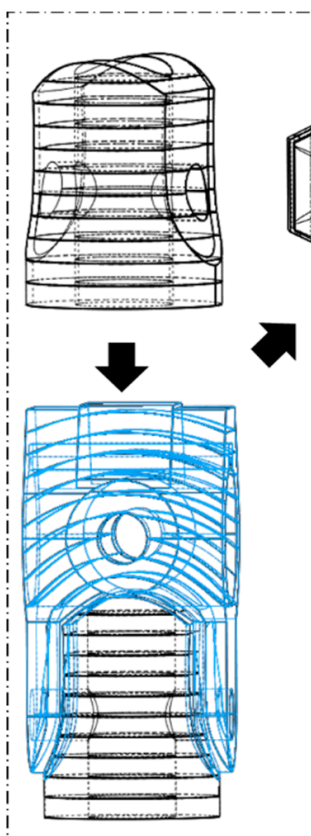

(1)

zation

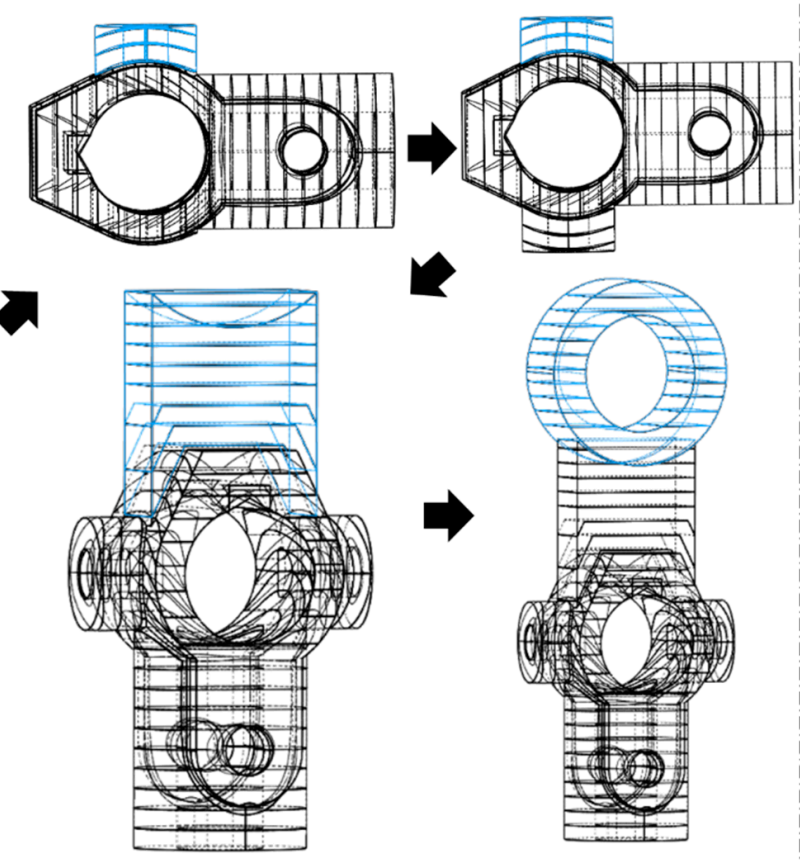

(c) Toolpath on Each processing volumes

Figure 13. Trajectory accumulation on model with second defined initial building orientation for model (a).

The below figure visualizes all the deposition trajectories on each single-body feature under the defined initial orientation.

The model is then processed with another selected initial orientation. Under this orientation, the Add volume is created through Algorithm 2 to prevent the global collision. The sequencing for processing single-body features is presented in Figure 12. 
Similarly, all deposited features' trajectories under the defined initial orientation are presented below.

By comparing Figures 10 and 12, the manufacturing features and associated sequence also varied based on different initial building orientations. The modification of the as-built geometry for avoiding the global collision condition is also dependent on the selection of the initial orientation.

Another model (b) (Figure 14 is processed through the proposed method that uses a robotic additive. The decomposed features are correctly assigned with the feasible processing sequencing without collisions are shown in Figure 14.

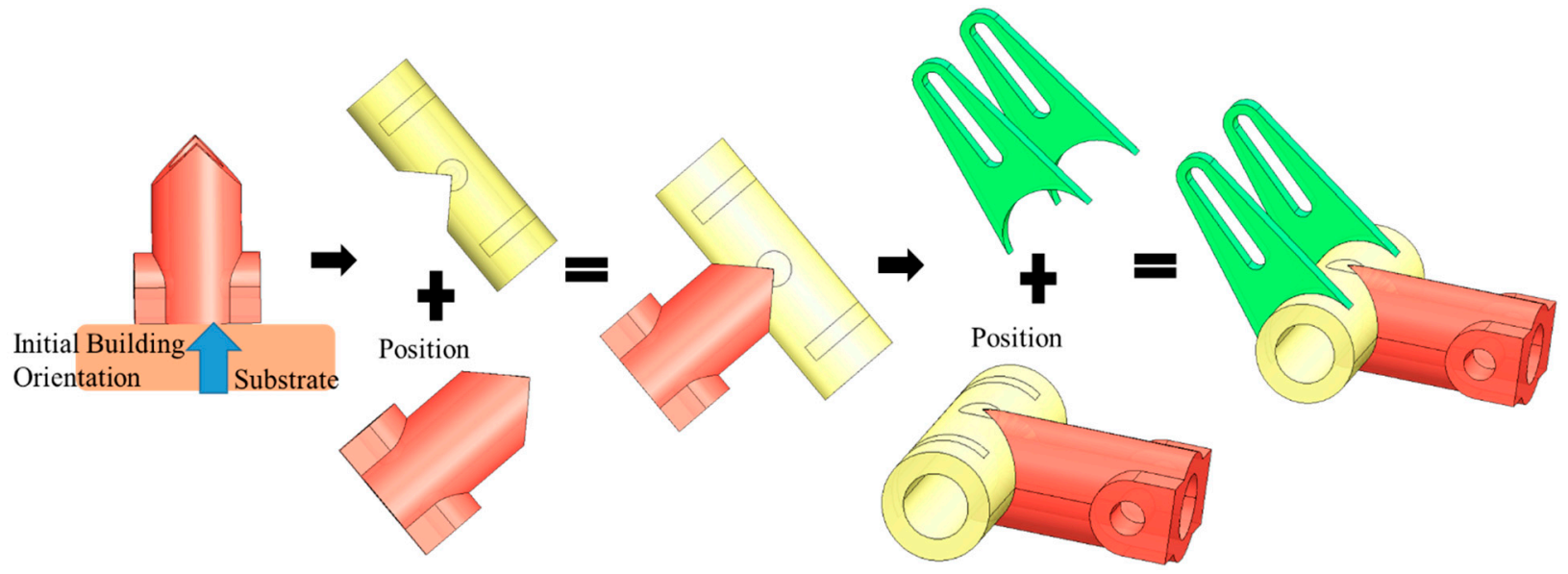

Figure 14. Process Planning with first defined initial building orientation for model (b).

The accumulated trajectories for this geometry are shown in Figure 15.

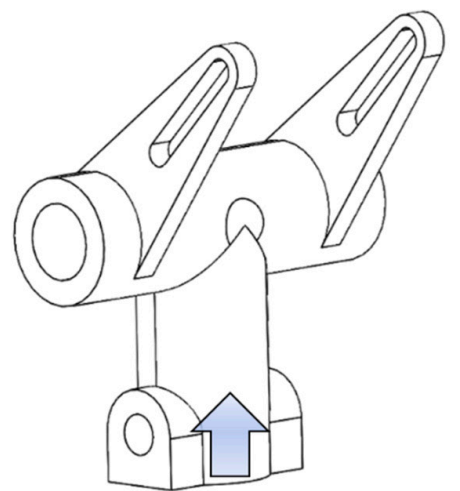

(a) Input Model with Initial Building Orientation!

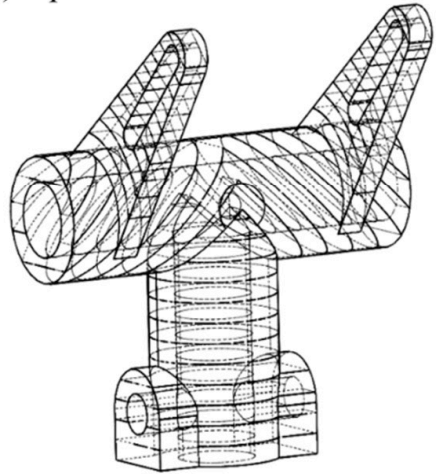

(b) Model Overall Toolpath Visualization

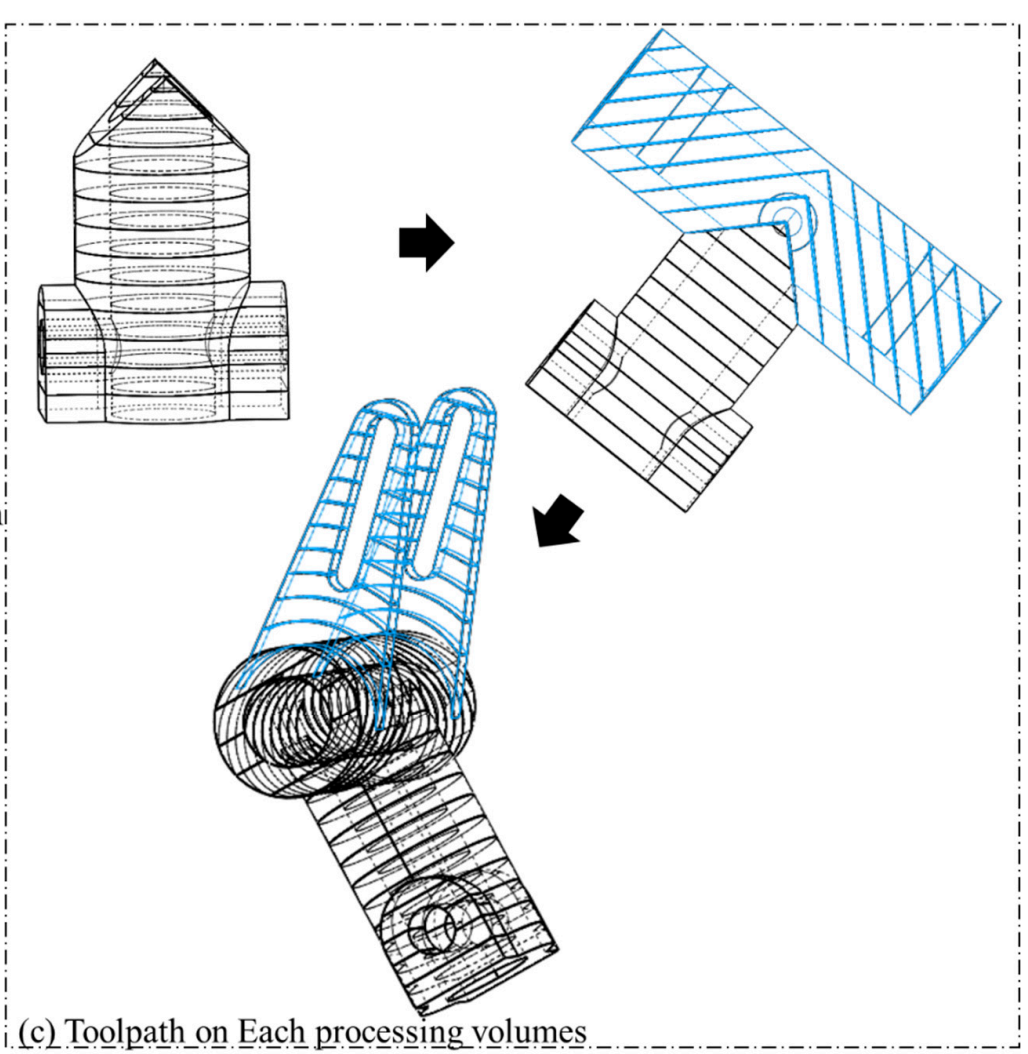

Figure 15. Trajectory accumulation on model with first defined initial building orientation for model (b). 
This model is then processed with another initial orientation which is shown in Figure 16. Under this orientation, the Add volumes (green volumes) are created through Algorithm 2 to prevent the global collision.
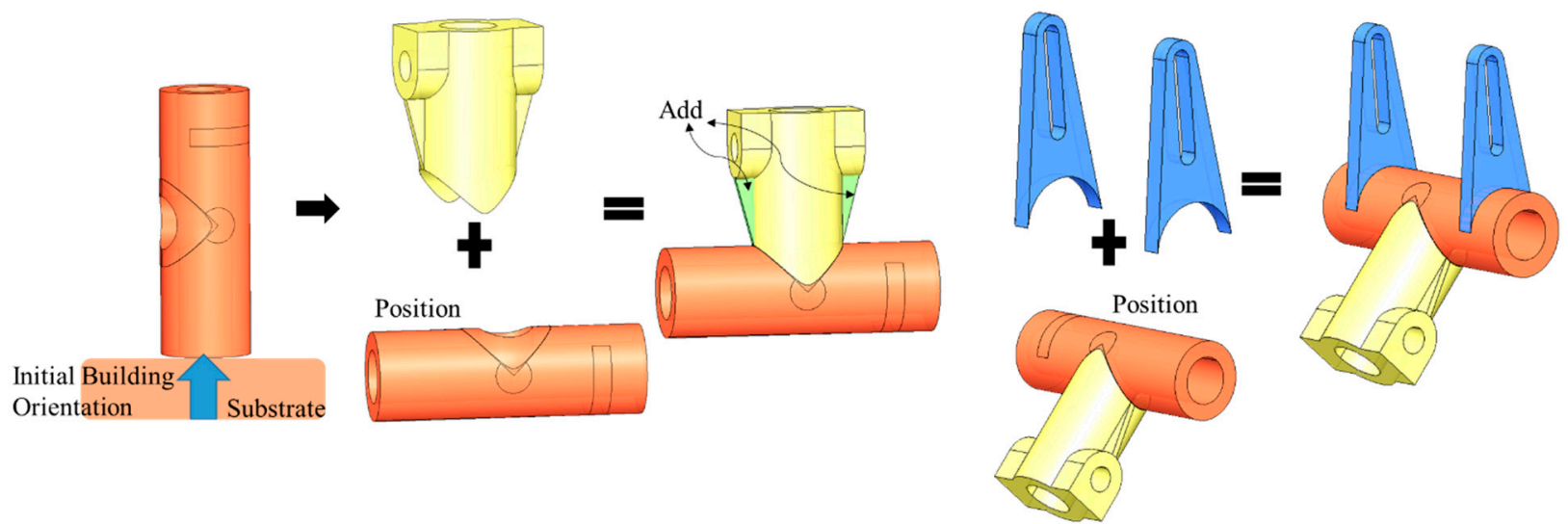

Figure 16. Process Planning with second defined initial building orientation for model (b).

The accumulated trajectories for this geometry, including the added volumes, are shown in Figure 17.

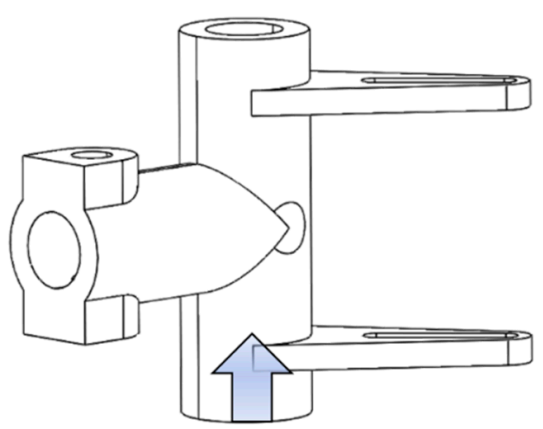

(a) Input Model with Initial Building Orientation

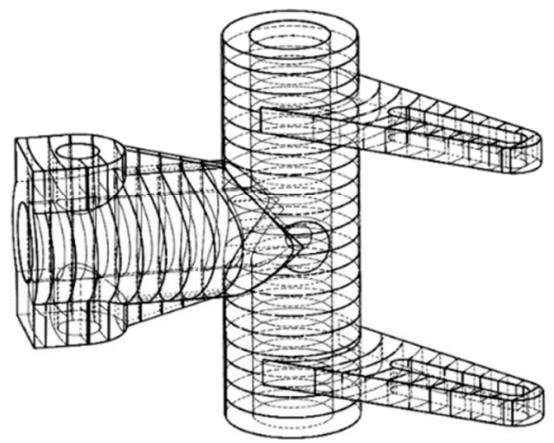

(b) Model Overall Toolpath Visualization

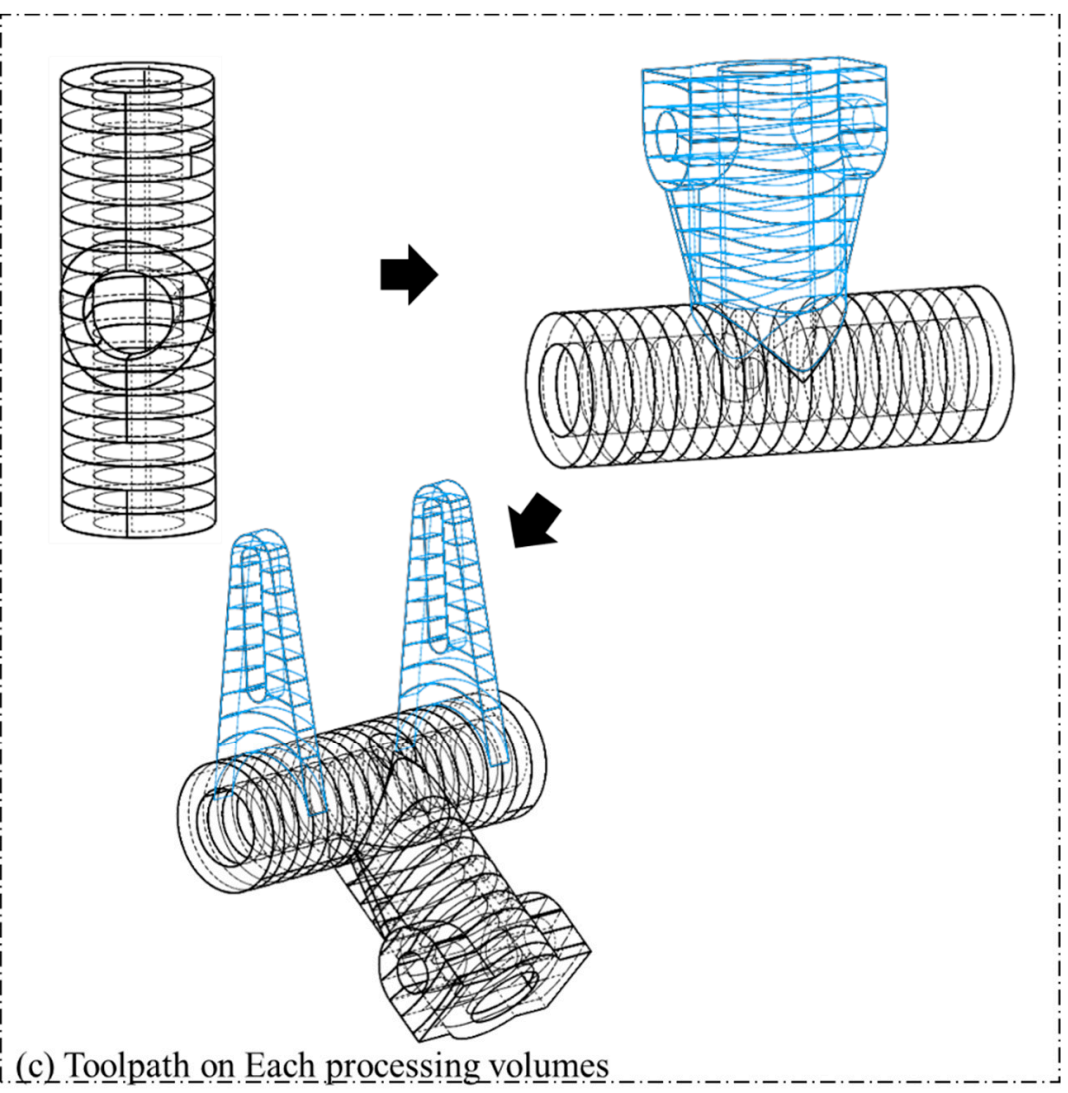

Figure 17. Trajectory accumulation on model with second defined initial building orientation for model (b).

Model (b) has been processed using the manufacturing strategy indicated in Figures 14 and 15. The machine that has been used in implementation is a fused deposition machine with a modified continuously rotary building platform to fulfill the robotic multiaxis material deposition capability. The overall printing process is presented in Figure 18. 
In addition, model (b) has been continuously oriented to sustain each single-body feature's supportless deposition manner.
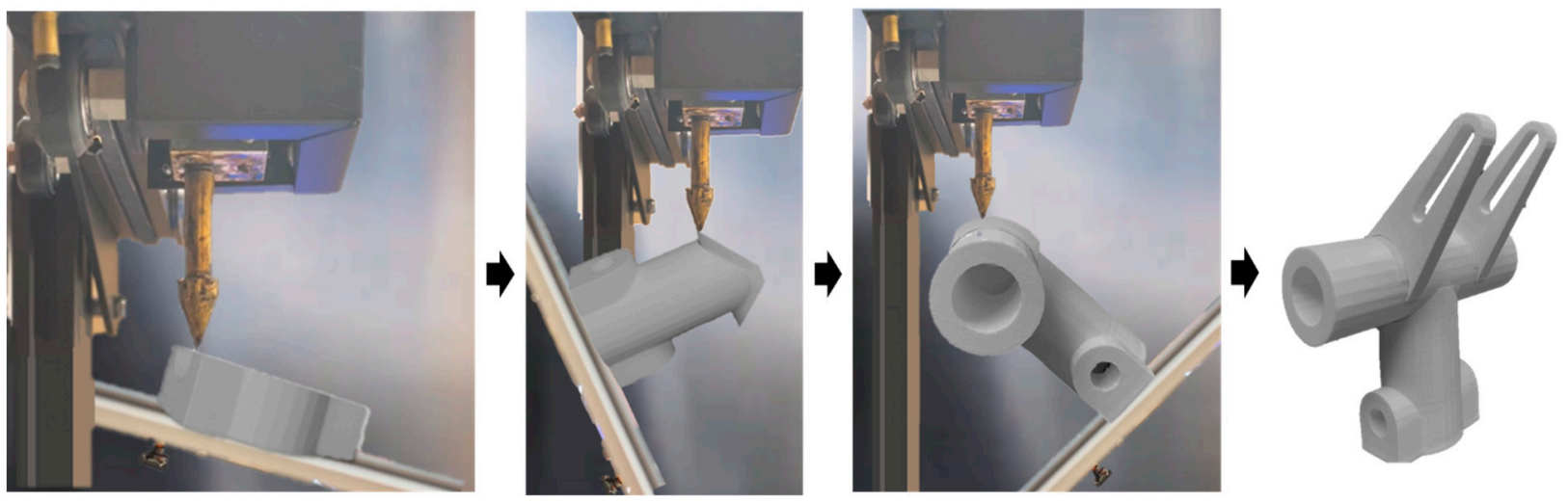

Figure 18. Printing Process for the model (b) in Figure 14.

The success of model (b) indicates the feasibility of the proposed autonomous manufacturing strategy on the robotic additive system, specifically for the metal additive process. The metal additive process, including the directed energy deposition and wire arc additive, has a small supportable overhang angle. Therefore, the supportless manner using the proposed robotic manufacturing method overcomes the metal AM manufacturability limitation without any extra human interpretation on the geometries.

\section{Discussion and Conclusions}

An autonomous feature-based manufacturing strategy is proposed, which utilizes robotic freeform fabrication. Autonomous deposition and accumulation on a freeform layer and continuously changing the building orientations in one process overcomes the limits in design, manufacturing, and human interpretation on the geometries. Current techniques of a multi-orientation additive process require heavy human intervention in specifying the additive features with orientations and trial and error in collision avoidance. The proposed method efficiently computes the single-body features for a given 3D model such that the part can be fabricated under the Boolean combination of these features on a robotic additive system in a collision-free and supportless manner. The proposed algorithms have been verified by simulating the multi-orientation freeform layer generations and the experimental implementations.

Future work will include the optimal computation on the process parameters for the metal robotic additive process to improve the quality and performance of the build. In addition, the proposed approach can be applied to Directed Energy Deposition (DED) with both powder and wire feed. Additional experiments using these are envisioned in the future to develop the proposed approach further.

Author Contributions: Conceptualization, X.X. and H.X.; methodology, X.X.; software, X.X.; validation, X.X. and H.X.; formal analysis, X.X.; investigation, X.X.; resources, X.X.; data curation, X.X.; writing-original draft preparation, X.X.; writing-review and editing, X.X., and H.X.; visualization, X.X.; supervision, X.X. and H.X.; project administration, H.X. All authors have read and agreed to the published version of the manuscript.

Funding: This research received no external funding.

Conflicts of Interest: The authors declare no conflict of interest. 


\section{References}

1. Wu, F.; Sun, Z.; Chen, W.; Liang, Z. The Effects of Overhang Forming Direction on Thermal Behaviors during Additive Manufacturing Ti-6Al-4V Alloy. Materials 2021, 14, 3749. [CrossRef]

2. Xiao, X.; Joshi, S. Decomposition and Sequencing for a 5-Axis Hybrid Manufacturing Process. In Proceedings of the International Manufacturing Science and Engineering Conference, Virtual, 3 September 2020; American Society of Mechanical Engineers: Leiden, The Netherlands, 2020; Volume 84256. Paper No: MSEC2020-8385, V001T01A049.

3. Sundaram, R.; Choi, J. A Slicing Procedure for 5-Axis LaserAided DMD Process. J. Manuf. Sci. Eng. 2004, 126, 632-636. [CrossRef]

4. Lee, K.; Jee, H. Slicing algorithms for multi-axis 3-D metal printing of overhangs. J. Mech. Sci. Technol. 2015, 29, 5139-5144. [CrossRef]

5. Chlebus, E.; Krot, K. CAD 3D models decomposition in manufacturing processes. Arch. Civ. Mech. Eng. 2016, 16, 20-29. [CrossRef]

6. Tao, S.; Wang, S.; Chen, A. 3D CAD solid model retrieval based on region segmentation. Multimed. Tools Appl. 2015, 76, 103-121. [CrossRef]

7. Golovinskiy, A.; Funkhouser, T. Consistent segmentation of 3D models. Comput. Graph. 2009, 33, 262-269. [CrossRef]

8. Liu, Z.; Tang, S.; Bu, S.; Zhang, H. New evaluation metrics for mesh segmentation. Comput. Graph. 2013, 37, 553-564. [CrossRef]

9. Jain, A.; Thormählen, T.; Ritschel, T.; Seidel, H.-P. Exploring Shape Variations by 3D-Model Decomposition and Part-based Recombination. Comput. Graph. Forum 2012, 31, 631-640. [CrossRef]

10. Rauch, M.; Hascoet, J.-Y.; Querard, V. A Multiaxis Tool Path Generation Approach for Thin Wall Structures Made with WAAM. J. Manuf. Mater. Process. 2021, 5, 128. [CrossRef]

11. NX. Available online: https://www.plm.automation.siemens.com/global/fr/products/nx/ (accessed on 16 April 2021).

12. Kapil, S.; Negi, S.; Joshi, P.; Sonwane, J.; Sharma, A.; Bhagchandani, R.; Karunakaran, K.P. 5-axis slicing methods for additive manufacturing process. In Annual International Solid Freeform Fabrication Symposium; UT Austin: Austin, TX, USA, 2017.

13. Luo, L.; Baran, I.; Rusinkiewicz, S.; Matusik, W. Chopper: Partitioning models into 3D-printable parts. ACM Trans. Graph. (TOG) 2012, 31, 1-9. [CrossRef]

14. Chen, X.; Golovinskiy, A.; Funkhouser, T. A benchmark for 3D mesh segmentation. ACM Trans. Graph. 2009, 28, 1-12. [CrossRef]

15. Wu, C.; Dai, C.; Fang, G.; Liu, Y.-J.; Wang, C.C.L. General Support-Effective Decomposition for Multi-Directional 3-D Printing. IEEE Trans. Autom. Sci. Eng. 2019, 17, 599-610. [CrossRef]

16. Murtezaoglu, Y.; Plakhotnik, D.; Stautner, M.; Vaneker, T.; van Houten, F.J. Geometry-Based Process Planning for Multi-Axis Support-Free Additive Manufacturing. Procedia CIRP 2018, 78, 73-78. [CrossRef]

17. Xiao, X.; Joshi, S. Process planning for five-axis support free additive manufacturing. Addit. Manuf. 2020, 36, 101569. [CrossRef]

18. Foskey, M.; Lin, M.C.; Manocha, D. Efficient Computation of A Simplified Medial Axis. J. Comput. Inf. Sci. Eng. 2003, 3, 274-284. [CrossRef]

19. Wu, C.; Dai, C.; Fang, G.; Liu, Y.-J.; Wang, C.C. RoboFDM: A robotic system for support-free fabrication using FDM. In Proceedings of the 2017 IEEE International Conference on Robotics and Automation (ICRA), Singapore, 29 May-3 June 2017; pp. 1175-1180.

20. Wei, X.; Qiu, S.; Zhu, L.; Feng, R.; Tian, Y.; Xi, J.; Zheng, Y. Toward Support-Free 3D Printing: A Skeletal Approach for Partitioning Models. IEEE Trans. Vis. Comput. Graph. 2018, 24, 2799-2812. [CrossRef]

21. Dai, C.; Wang, C.C.L.; Wu, C.; Lefebvre, S.; Fang, G.; Liu, Y.-J. Support-free volume printing by multi-axis motion. ACM Trans. Graph. 2018, 37, 1-14. [CrossRef]

22. Tsuzuki, M.D.S.G.; Takase, F.K.; Garcia, M.A.S.; Martins, T.D.C. Converting CSG models into meshed B-Rep models using euler operators and propagation based marching cubes. J. Braz. Soc. Mech. Sci. Eng. 2007, 29, 337-344. [CrossRef]

23. Kapil, S.; Joshi, P.; Kulkarni, P.M.; Negi, S.; Kumar, R.; Karunakaran, K. Elimination of support mechanism in additive manufacturing through substrate tilting. Rapid Prototyp. J. 2018, 24, 1155-1165. [CrossRef]

24. LASERTEC 65 Ded Hybrid. DMG MORI USA-CNC Machine Tools for All Cutting Machining Applications. (n.d.)Retrieved 17 November 2021 Available online: https://us.dmgmori.com/products/machines/additive-manufacturing/powder-nozzle/ lasertec-65-3d-hybrid (accessed on 15 December 2021).

25. Hybrid Manufacturing Technologies. (19 January 2021)Retrieved 17 November 2021. Available online: http://www. hybridmanutech.com/ (accessed on 15 December 2021).

26. Ren, L.; Sparks, T.; Ruan, J.; Liou, F. Process planning strategies for solid freeform fabrication of metal parts. J. Manuf. Syst. 2008, 27, 158-165. [CrossRef]

27. Liu, C.; Li, Y.; Jiang, S.; Li, Z.; Xu, K. A sequence planning method for five-axis hybrid manufacturing of complex structural parts. Proc. Inst. Mech. Eng. Part B J. Eng. Manuf. 2019, 234, 421-430. [CrossRef]

28. Huang, B.; Singamneni, S. A mixed-layer approach combining both flat and curved layer slicing for fused deposition modelling. Proc. Inst. Mech. Eng. Part B J. Eng. Manuf. 2015, 229, 2238-2249. [CrossRef]

29. Schmitz, M.; Wiartalla, J.; Gelfgren, M.; Mann, S.; Corves, B.; Hüsing, M. A Robot-Centered Path-Planning Algorithm for Multidirectional Additive Manufacturing for WAAM Processes and Pure Object Manipulation. Appl. Sci. 2021, 11, 5759. [CrossRef]

30. Xiao, X.; Roh, B.-M.; Zhu, F. Strength Enhancement in Fused Filament Fabrication via the Isotropy Toolpath. Appl. Sci. 2021, 11, 6100. [CrossRef]

31. Zhang, W.; Soshi, M.; Yamazaki, K. Development of an additive and subtractive hybrid manufacturing process planning strategy of planar surface for productivity and geometric accuracy. Int. J. Adv. Manuf. Technol. 2020, 109, 1479-1491. [CrossRef] 
32. Micali, M.K.; Dornfeld, D. Fully three-dimensional toolpath generation for point-based additive manufacturing systems. In Solid Freeform Fabrication Symposium; UT Austin: Austin, TX, USA, 2016; Volume 27.

33. Zhang, G.Q.; Mondesir, W.; Martinez, C.; Li, X.; Fuhlbrigge, T.A.; Bheda, H. Robotic additive manufacturing along curved surface-A step towards free-form fabrication. In Proceedings of the 2015 IEEE International Conference on Robotics and Biomimetics (ROBIO), Zhuhai, China, 6-9 December 2015; pp. 721-726.

34. Song, X.; Pan, Y.; Chen, Y. Development of a Low-Cost Parallel Kinematic Machine for Multidirectional Additive Manufacturing. J. Manuf. Sci. Eng. 2015, 137, 021005. [CrossRef]

35. Fang, H.; Ong, S.; Nee, A. Robot path planning optimization for welding complex joints. Int. J. Adv. Manuf. Technol. 2017, 90, 3829-3839. [CrossRef]

36. Wang, H.; Stori, J.A. A Metric-Based Approach to 2D Tool-Path Optimization for High-Speed Machining. In Manufacturing; American Society of Mechanical Engineers: New Orleans, LA, USA, 2002; Volume 3641, pp. 139-148.

37. Alsharhan, A.T.; Centea, T.; Gupta, S.K. Enhancing Mechanical Properties of Thin-Walled Structures Using Non-Planar Extrusion Based Additive Manufacturing. In Proceedings of the ASME 2017 12th International Manufacturing Science and Engineering Conference 2017, Los Angeles, CA, USA, 4-8 June 2017. [CrossRef]

38. Shembekar, V.; Yoon, Y.J.; Kanyuck, A.; Gupta, S.K. Generating Robot Trajectories for Conformal 3D Printing Using Non-Planar Layers. J. Comput. Inf. Sci. Eng. 2019, 19, 031011. [CrossRef]

39. Zhao, G.; Ma, G.; Feng, J.; Xiao, W. Nonplanar slicing and path generation methods for robotic additive manufacturing. Int. J. Adv. Manuf. Technol. 2018, 96, 3149-3159. [CrossRef]

40. Bhatt, P.M.; Kabir, A.M.; Malhan, R.K.; Shah, B.; Shembekar, A.V.; Yoon, Y.J.; Gupta, S.K. A Robotic Cell for Multi-Resolution Additive Manufacturing. In Proceedings of the International Conference on Robotics and Automation (ICRA), Montreal, QC, Canada, 20-24 May 2019.

41. Davis, J.D.; Kutzer, M.D.; Chirikjian, G.S. Algorithms for Multilayer Conformal Additive Manufacturing. J. Comput. Inf. Sci. Eng. 2016, 16, 021003. [CrossRef]

42. Pan, Y.; Zhou, C.; Chen, Y.; Partanen, J. Multitool and Multi-Axis Computer Numerically Controlled Accumulation for Fabri-cating Conformal Features on Curved Surfaces. J. Comput. Inf. Sci. Eng. 2014, 136, 031007.

43. Chakraborty, D.; Reddy, B.A.; Choudhury, A.R. Extruder path generation for Curved Layer Fused Deposition Modeling. Comput. Des. 2008, 40, 235-243. [CrossRef]

44. Shembekar, A.V.; Yoon, Y.J.; Kanyuck, A.; Gupta, S.K. Trajectory Planning for Conformal 3D Printing Using Non-Planar Layers In Proceedings of the ASME International Design Engineering Technical Conferences and Computers and Information in Engi-neering Conference; ASME International: Quebec, QC, Canada, 2018; Volume 1A.

45. Xiao, X.; Joshi, S. Automatic toolpath generation for heterogeneous objects manufactured by directed energy deposition additive manufacturing process. J. Manuf. Sci. Eng. 2018, 140, 071005. [CrossRef]

46. Roh, B.M.; Kumara, S.R.; Witherell, P.; Simpson, T.W. Ontology-based Process Map for Metal Additive Manufacturing. J. Mater. Eng. Perform. 2021, 1-14. [CrossRef]

47. Roh, B.M.; Kumara, S.R.; Yang, H.; Simpson, T.W.; Witherell, P.; Lu, Y. In-Situ Observation Selection for Quality Management in Metal Additive Manufacturing. In International Design Engineering Technical Conferences and Computers and Information in Engineering Conference; V002T02A069; American Society of Mechanical Engineers: New York, NY, USA, 2021; Volume 85376. 